\title{
Effectiveness of COVID-19 vaccines and their challenges (Review)
}

\author{
GABRIELLA MARFE $^{1}$, STEFANIA PERNA $^{1}$ and ARVIND KUMAR SHUKLA ${ }^{2,3}$ \\ ${ }^{1}$ Department of Environmental, Biological and Pharmaceutical Sciences and Technologies, \\ University of Campania 'Luigi Vanvitelli', 81100 Caserta, Italy; ${ }^{2}$ School of Biomedical Convergence \\ Engineering, Pusan National University, Yangsan, Gyeongsangnam-do 50612, Republic of Korea; \\ ${ }^{3}$ Inventra Medclin Biomedical Healthcare and Research Center, Katemanivli, Kalyan, Thane, Maharashtra 421306, India
}

Received May 17, 2021; Accepted August 24, 2021

DOI: $10.3892 / \mathrm{etm} .2021 .10843$

\begin{abstract}
At the end of 2019, a new disease recognized such as severe acute respiratory syndrome (SARS), was reported in Wuhan, China. This disease was caused by an unknown SARS coronavirus 2 (SARS-CoV-2); a virus is characterized by high infectivity among humans. In some cases, this disease can be asymptomatic, while in other cases can induce flu-like symptoms or acute respiratory distress syndrome, pneumonia and death. For this reason, the World Health Organization and Public Health Emergency of International Concern declared a pandemic status in January 2020. Currently, numerous countries have been involved in the development of effective vaccines to protect humans against SARS-CoV-2 infection. The present review will discuss the four vaccines, AZD1222 (AstraZeneca or Vaxzevria), Janssen (Ad26.COV2.S), Moderna/mRNA-1273 and BioNTech/Fosun/Pfizer BNT162b1, that are currently in use worldwide to understand their efficacy, but also evaluate the difficulties and challenges of vaccine development. Although several questions should be addressed regarding these vaccines, the current review will examine the viral elements used in the coronavirus-19 vaccine that can play a crucial role in inducing a strong immune response, as well as the different adverse effects that they can cause to individuals.
\end{abstract}

\section{Contents}

1. The current history of COVID-19

2. Efficacy and adverse events of COVID-19 vaccines

3. Mass vaccination

4. Remaining questions regarding mRNA vaccines

5. Conclusions

Correspondence to: Dr Gabriella Marfe, Department of Environmental, Biological and Pharmaceutical Sciences and Technologies, University of Campania 'Luigi Vanvitelli', Via Vivaldi 43, 81100 Caserta, Italy

E-mail: gabmarfe@alice.it

Key words: coronavirus-19, vaccines, mRNA, pandemic, immunity, adverse effects

\section{The current history of COVID-19}

Since December 2019, numerous cases of atypical pneumonia were registered in Wuhan, China $(1,2)$, and these were attributed to a novel coronavirus referred to as coronavirus-19 (COVID-19). Since January 2020, the number of COVID-19 cases has increased significantly worldwide, and thus, the World Health Organization (WHO) declared a pandemic on January 31st 2020. At present, the emergence of this virus is a significant threat to worldwide public health. On August 18th 2021, data obtained revealed that since the start of the outbreak, 208,470,375 individuals have been diagnosed with severe acute respiratory syndrome coronavirus 2 (SARS-CoV-2) infection globally, and 4,377,979 deaths have been reported by the WHO. Moreover, as of 18th August 2021 (at 6.39 p.m.) a total of 4,543,716,443 vaccine doses had been administered (3).

Based on the latest scientific literature (1,2), SARS-CoV-2 can infect humans and spread easily and rapidly after its binding with the human angiotensin-converting enzyme 2 (ACE2) receptor. The binding between the spike protein and ACE2 occurs via proteolytic cleavage of ACE2 by transmembrane serine protease 2 . After binding, the enzyme converts angiotensin I into angiotensin 1-9, which in turn is converted to angiotensin 1-7 that acts on the Mas receptor (a G protein-coupled receptor). Specifically, this receptor is expressed in a variety of cell lineages in several tissues relevant to cardiovascular disease (including type 2 alveolar epithelial cells) and can lower blood pressure via vasodilation and promote kidney sodium and water excretion, as well as attenuate inflammation via the production of nitric oxide 3 . Previous studies have suggested that the viral entry through the binding of the SARS-CoV-2 spike protein to ACE2 could suppress ACE2 expression. This process could lead to elevated internalization and shedding of ACE2 from the cell surface, which in turn could increase levels of angiotensin II. Angiotensin II binds to its receptor AT1, thereby causing an inflammatory response in the lungs and potentially triggering direct parenchymal injury. Furthermore, ACE2 receptors are expressed in the heart (endothelium of coronary arteries, myocytes, fibroblasts and epicardial adipocytes), vessels (vascular endothelial and smooth cells), gut (intestinal epithelial cells), lungs (tracheal and bronchial epithelial cells, type 2 pneumocytes, macrophages), kidneys (luminal surface of 
tubular epithelial cells), testis and brain (4-8). Another study identified a fragment of the receptor-binding domain (RBD) in the SARS-CoV-2 spike protein that may be the most important determinant of the SARS-CoV host range (9). In another report, Coutard et al (10) observed a furin-like cleavage sequence site (PRRARSIV) in the spike protein of the SARS-CoV-2, which was also present in the Middle East respiratory syndrome (MERS)-CoV. In a recent article, a D614G mutation in the spike protein of SARS-CoV-2 was identified, this protein containing different amino acid at residue 614 [aspartic acid (SD614) and glycine (SG614)] was evaluated (11). It was found that pseudotyped retrovirus with the mutation SG614 was more efficient in infecting ACE2-expressing cells compared with those with SD614 (11).

Some SARS-CoV-2-infected patients may be asymptomatic, or they may display different types of symptoms, such as fever, gastrointestinal or respiratory symptoms, particularly in vulnerable population groups, such as the elderly or individuals with other underlying conditions. The immune system plays a crucial role in helping to overcome the disease, but numerous infected patients show a hyperactivated immune response, which can lead to respiratory insufficiency and other complications, such as thrombotic or thromboembolic events (12). SARS-CoV-2 is able to activate both the innate and acquired immune response (12). The virus-specific antibodies, including immunoglobulin $(\mathrm{Ig}) \mathrm{G}$ and $\operatorname{IgM}$, are produced by $\mathrm{CD}^{+} \mathrm{T}$ cells that, in turn, stimulate $\mathrm{B}$ cells, while $\mathrm{CD}^{+} \mathrm{T}$ cells kill virus-infected cells. Furthermore, pro-inflammatory cytokines and mediators are produced by $\mathrm{T}$ helper (Th) cells to help the other immune cells. This virus can induce the programmed cell death of $\mathrm{T}$ cells by blocking the immune defense (12). In this regard, the host's production of complement factors, such as $\mathrm{C} 3 \mathrm{a}$ and $\mathrm{C} 5 \mathrm{a}$, and antibodies are important to fight the viral infection (12). In some patients, the virus induces a strong host response or overreaction of the immune system, leading to the production of high levels of different inflammatory cytokines and chemokines, which provoke severe damage to the lungs and other organs. In this scenario, this abnormal production of cytokines and chemokines causes multi-organ failure and even mortality (12). Generally, acute respiratory distress syndrome (ARDS) causes mortality in patients with COVID-19 (12). Clinical reports have shown that both mild and severe forms of this disease can result in changes in circulating leukocyte subsets and cytokine secretion, particularly IL-6, IL-1 $\beta$, IL-10, TNF, granulocyte-macrophage colony stimulating factor, IFN-induced protein 10, IL-17, monocyte chemoattractant protein 3 and IL-1ra. Once immunologic complications such as the cytokine storm occur, anti-viral treatment alone is not sufficient and should be combined with appropriate anti-inflammatory treatment (12).

Most patients with COVID-19 develop mild or uncomplicated symptoms (including fever cough and fatigue), while $\sim 14 \%$ of individuals can have severe disease, requiring hospitalization and oxygen support, and 5\% require admission to an intensive care unit (ICU). In severe cases, patients can develop ARDS, sepsis and septic shock, and multi-organ failure, including acute kidney injury and cardiac injury. Previous studies have reported the association between abnormal cytokine levels and disease progression, including coagulation-related markers, such as D-dimer and fibrinogen, neutrophil count, lymphocyte count and high-sensitivity C-reactive protein (13-18). However, these indicators are not sufficient to predictive the severity of COVID-19, since other factor such as insufficient information, individual differences and disease complexity should be considered $(19,20)$. In this regard, previous studies have developed prediction models from retrospective, single-centre data to allow for an effective decision-making process for patients with COVID-19 in medical emergency rooms and at hospital admission. Therefore, the development of effective prediction models can play an important role in implementing rapid response interventions, thereby reducing mortality (19-24).

Previous studies are also designing various diagnostic tests, antiviral agents and vaccines based on the current understanding of the structure and function of the various viral proteins involved in the life cycle of SARS-CoV-2 $(25,26)$. At present, the development of COVID-19 vaccines may be the only way to overcome this disease. Candidate immunogens may be presented in various forms, such as live-attenuated whole organisms, killed or inactivated whole organisms, and subunit vaccines. Specifically, the subunit vaccines contain selected fragments of the pathogen as antigens. Generally, proteins, polysaccharides or parts of a virus that may form virus-like particles (VLPs) represent these fragments (such as tetanus toxoid, inactivated split and subunit seasonal influenza, acellular pertussis and pneumococcal polysaccharide vaccines). The best-known examples of VLPs are human papillomavirus (HPV). Moreover, vectored genes encode protein antigens, such as the hepatitis B vaccine in which the gene of the hepatitis B surface antigen has been inserted into appropriate vectors for production in yeast (Engerix-B, GSK; Recombivax-HB, MSD) or mammalian cells (GenHevac-B, Sanofi Pasteur) (25). Furthermore, VLP vaccines are based on the observation that the expression of certain viral proteins leads to the spontaneous assembly of particles structurally similar to the original viruses. VLPs are not infectious as they lack the viral genome. However, the native conformation of the antigenic proteins is well preserved, which improves their immunogenicity compared with free proteins. Reverse vaccinology is a new technology in which genes encoding potential antigenic proteins are identified from the entire genome of a given pathogen The identified proteins are then tested in vitro and in vivo to determine whether they are immunogenic and induce protective antibodies. Reverse vaccinology has been used to develop a vaccine against the challenging Neisseria meningitidis serogroup B $(25,26)$. Furthermore, with regards to the typhoid vaccine, there are two types: i) In the parenteral (intramuscular) formulation, in which the vaccine contains the polysaccharide antigen (an inactive vaccine), such as purified capsular polysaccharides of Salmonella typhi (Ty2 strain); and ii) in the oral formulation, which is a vaccine that contains the live attenuated strain known as Salmonella typhi Ty21a; (live attenuated), such as that for the Sabin-type polio vaccine or the typhoid fever vaccine.

Despite the recent successful developments in vaccine design, no vaccine provides absolute or life-long protection for the vaccinated individuals. In some cases, vaccines fail to induce a protective immune response $(27,28)$. Currently, $\sim 100$ candidate SARS-CoV-2 vaccines are under development, as reported by the WHO (29). The surface membrane 
Table I. Information regarding COVID-19 vaccine platforms and trials.

\begin{tabular}{|c|c|c|c|c|c|}
\hline Developer & $\begin{array}{l}\text { Vaccine } \\
\text { name }\end{array}$ & $\begin{array}{l}\text { Antigen } \\
\text { spike }\end{array}$ & Platform & $\begin{array}{l}\text { Clinical } \\
\text { stage }\end{array}$ & Clinical trial identifier \\
\hline Sinovac Biotech Ltd. & CoronaVac & $\mathrm{S}$ & Inactivated virus & Phase III/IV & $\begin{array}{l}\text { NCT04800133 } \\
\text { NCT04651790 } \\
\text { NCT04456595 } \\
\text { NCT04508075-669/ } \\
\text { UN6.KEP/EC/2020 } \\
\text { NCT04582344 } \\
\text { NCT04617483 } \\
\text { PHRR210210-003308 }\end{array}$ \\
\hline Sinopharm & BBIBP-CorV & $\mathrm{S}$ & Inactivated virus & Phase III & $\begin{array}{l}\text { NCT04510207 } \\
\text { ChiCTR2000034780 } \\
\text { NCT04612972 } \\
\text { NCT04560881, } \\
\text { BIBP2020003AR }\end{array}$ \\
\hline $\begin{array}{l}\text { University of Oxford/ } \\
\text { AstraZeneca plc }\end{array}$ & $\begin{array}{l}\text { ChAdOx1 } \\
\text { nCov-19 } \\
\text { (AZD1222) }\end{array}$ & $\mathrm{S}$ & $\begin{array}{l}\text { Chimpanzee } \\
\text { adenoviral vector }\end{array}$ & Phase III & $\begin{array}{l}\text { NCT04864561 } \\
\text { CTRI/2020/08/027170 } \\
\text { NCT04800133 } \\
\text { ISRCTN89951424, } \\
\text { NCT04536051 } \\
\text { NCT04516746 } \\
\text { EUCTR2020-001228-32, } \\
\text { NCT04400838 } \\
\text { NCT04540393 }\end{array}$ \\
\hline $\begin{array}{l}\text { Gamaleya Research } \\
\text { Institute of } \\
\text { Epidemiology and } \\
\text { Microbiology }\end{array}$ & & $\mathrm{S}$ & $\begin{array}{l}\text { Human } \\
\text { adenoviral vector }\end{array}$ & Phase III & $\begin{array}{l}\text { NCT04640233 } \\
\text { NCT04642339 } \\
\text { NCT04656613 } \\
\text { NCT04741061 } \\
\text { NCT04564716 } \\
\text { NCT04530396 }\end{array}$ \\
\hline $\begin{array}{l}\text { Janssen Pharmaceuticals/ } \\
\text { Johnson \& Johnson }\end{array}$ & Ad26.COV2.S & $\mathrm{S}$ & $\begin{array}{l}\text { Human } \\
\text { adenoviral vector }\end{array}$ & Phase III & $\begin{array}{l}\text { NCT04505722, } \\
\text { NCT04614948, } \\
\text { ISRCTN14722499 }\end{array}$ \\
\hline CanSino Biologics, Inc. & Ad5-nCoV & $\mathrm{S}$ & $\begin{array}{l}\text { Human } \\
\text { adenoviral vector }\end{array}$ & Phase III & $\begin{array}{l}\text { NCT04526990, } \\
\text { NCT04540419 }\end{array}$ \\
\hline Moderna, Inc. & mRNA-1273 & $\mathrm{S}$ & mRNA & Phase III & $\begin{array}{l}\text { NCT04860297 } \\
\text { NCT04806113 } \\
\text { NCT04649151 } \\
\text { NCT04470427 } \\
\text { NCT04796896 } \\
\text { NCT04811664 } \\
\text { NCT04805125 }\end{array}$ \\
\hline BioNTech SE/Pfizer, Inc. & BNT162b2 & $\mathrm{S}$ & mRNA & Phase III & $\begin{array}{l}\text { NCT04368728 } \\
\text { NCT04805125 } \\
\text { NCT04800133 } \\
\text { NCT04816669 } \\
\text { NCT04713553 } \\
\text { NCT04754594 }\end{array}$ \\
\hline
\end{tabular}

S, spike.

spike protein (also known as the $\mathrm{S}$ protein), is the target of most vaccines as it is involved in the entry of host cells. The optimum method to create a vaccine is based on viral inactivation, and is used in both bacterial and viral diseases, such 
A

Vaccine $\longrightarrow$ Immune response

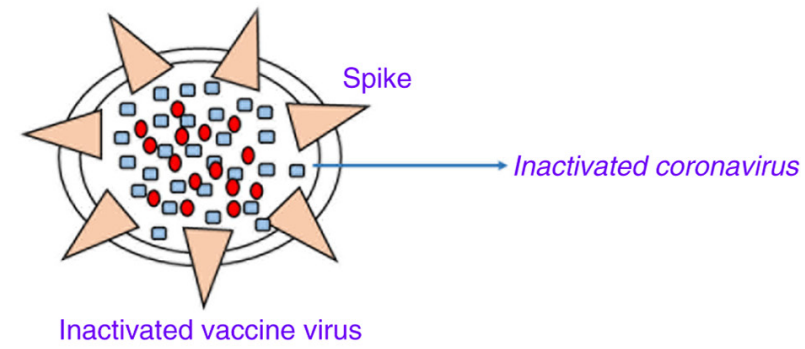

Q Efficacy: $50 \%$ (original strain)
Dosing: 2 doses -14 days
$\square$ Storage: $+2-8{ }^{\circ} \mathrm{C}$

B
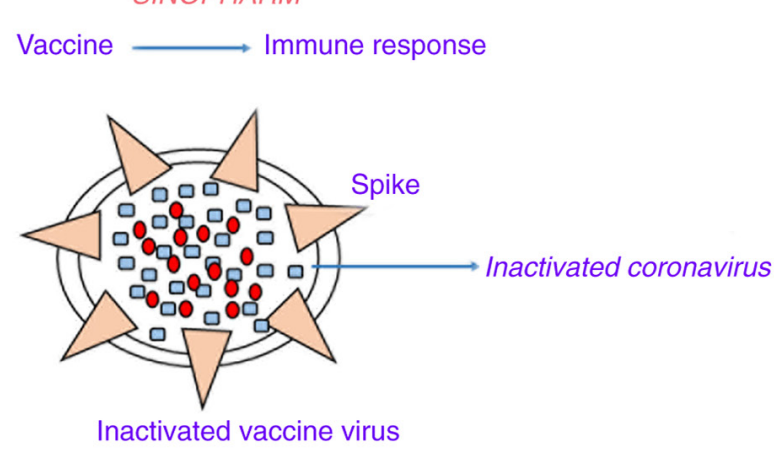

a Efficacy: $79 \%$ (original strain)
Dosing: 2 doses -21 days
$\square$ Storage: $+2-8{ }^{\circ} \mathrm{C}$

Figure 1. Details of two coronavirus-19 vaccines based on the whole inactivated severe acute respiratory syndrome coronavirus 2. (A) Sinovac vaccine. (B) Sinopharm vaccine.

as typhoid, influenza and HPV (27). Viruses are first grown in mammalian cell culture and then they are inactivated with different chemicals, such as formaldehyde or $\beta$-propiolactone. This method is easy, but its yield depends on the requirement of biosafety level 3 facilities (27). However, the entire virion may induce non-neutralizing antibodies (non-NAbs) and introduce the risk of antibody-dependent enhancement (ADE) (30). To the best of our knowledge, two companies in China, namely Sinovac and Sinopharm, have used viral inactivation to develop two vaccines, which are currently at phase III trials (Table I).

CoronaVac. CoronaVac (formerly PiCoVacc) (Fig. 1A), manufactured by Sinovac, is an inactivated viral vaccine with the addition of an alum adjuvant. In the development of this vaccine, initially, a sample of the SARS-CoV-2 strain $\mathrm{CN} 2$ was derived from bronchoalveolar lavage (BAL) of a hospitalized patient in Wuhan, China. This virus strain sample was cultured in vero cells, harvested and inactivated by $\beta$-propiolactone. Then, the inactivated viruses were mixed with aluminum hydroxide after purification (31). In the phase I study, 144 healthy adults, aged 18-59 years old, were enrolled and the investigators identified that the resulting seroconversion was $>75 \%$ in all subjects. At screening, participants were initially divided into two vaccination groups (days 0 and 14 vaccination group and days 0 and 28 vaccination group) and within each group, the first 36 participants received low dose CoronaVac ( $3 \mu \mathrm{g}$ per $0.5 \mathrm{ml}$ aluminum hydroxide diluent per dose; Block 1) then another 36 individuals received high-dose CoronaVac $(6 \mu \mathrm{g}$ per $0.5 \mathrm{ml}$ aluminum hydroxide diluent per dose; Block 2). In the phase II study, seroconversion was $>95 \%$ in 600 subjects after improvement of purification method (32). Furthermore, the antibody levels were elevated after two doses (day 0 and 28) with the $6 \mu \mathrm{g}$ vaccine, but in the phase III study, the concentration of $3 \mu \mathrm{g}$ was decided due to production capacity (the seroconversion was 100 and 97\%, respectively). However, the antibody levels [calculated using geometric mean titer (GMT) of neutralizing spike IgG] were lower in comparison with human convalescent serum. In this regard, the low immunogenicity of this vaccine may be due to both viral inactivation of the vaccine and alteration of the spike protein caused by chemicals (as aforementioned). A pre-clinical study in rhesus macaques found that an antibody titer of $1 / 24$ was able to protect against SARS-CoV-2 infection (31). In a Brazilian trial, the Chinese manufacturing company (Sovac) identified an efficacy level of $50.38 \%$ at preventing symptomatic infections (33). Additional trials in other countries have reported higher efficacies, such as those of 83.5 and $65.3 \%$ in Turkey (34) and Indonesia (35), respectively.

BBIBP-CorV. BBIBP-CorV, manufactured by Sinopharm, was developed by inactivating the virus with alum (Fig. 1B). In this vaccine, the SARS-CoV-2 virus strain $\mathrm{HB} 02$ was derived from a BAL sample of a hospitalized patient in Wuhan, China (36). This virus strain was cultured in Vero cells, harvested and inactivated using $\beta$-propiolactone. The inactivated strain was then mixed with aluminum hydroxide after purification (36). In a phase I study, 192 subjects (aged $>60$ years old) were recruited, and they did not have any reported serious adverse events. Next, the phase III study reported higher immunogenicity than that of Sinovac, with 100\% seroconversion achieved in all ( 448) subjects. In this case, NAb levels calculated with GMT were 282.7. Moreover, further phase I/II trials showed that two doses (day 0 and 28) of $4 \mu \mathrm{g}$ BBIBP-CorV were able to produce elevated NAbs titer with respect to other tested doses $8 \mu \mathrm{g}(37)$.

Other candidate SARS-CoV-2 vaccines. Other candidate SARS-CoV-2 vaccines under development are based on viral vectors. Replicating or non-replicating viral vectors can be used to introduce viral material into cells. This viral material is transcribed, translated into viral proteins and then presented to the immune system via major histocompatibility complex I (38). Numerous replicating vectors have been used and approved for Ebola (rVSV-ZEBOV, a vesicular stomatitis virus) (39) and dengue virus (Dengvaxia, a chimeric yellow fever virus) (40). Among the non-replicating vectors, Ad26 (41) has been used 
A

ChAd01222 (Covidshield) Oxford/AstraZeneca

Vaccine (Adenovirus)

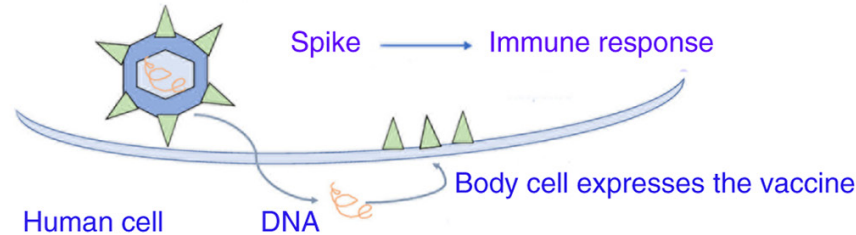

Human cell
B

\section{JMJ-7846738/Ad26.COV.s Johnson\&Johnson}

Vaccine (Adenovirus) Ad26

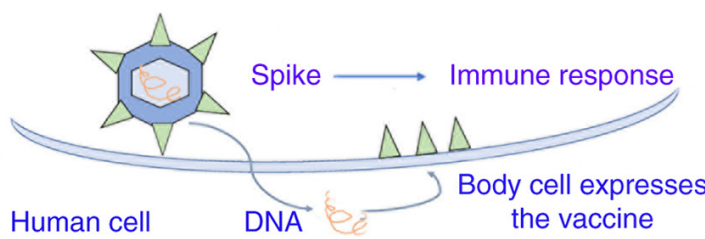

‘्र Efficacy:72\% (original strain)

Dosing: 1 dose

[ Storage: $+2-8{ }^{\circ} \mathrm{C} 3$ months

Figure 2. Coronavirus-19 vaccines based on spike protein DNA carried by adenoviruses. (A) AZD1222 vaccine (chimpanzee adenovirus: AstraZeneca, University of Oxford, Sweden-UK-Italy). (B) Janssen (Ad26.COV2.S human adenoviruses).

and approved for the Ebola virus in the European Union (EU). At present, four COVID-19 vaccines are using non-replicating vectors (adenoviral-based) and they are undergoing phase III study, including: Oxford/AstraZeneca plc (Chimpanzee Ad), Gamaleya Research Institute of Epidemiology and Microbiology (Ad5/Ad26), Janssen Pharmaceuticals, Inc./Johnson \& Johnson (Ad26) and CanSino (Ad5) (Table I).

ChAdOxl nCoV19 (or AZD1222). ChAdOx1 nCoV19 (or AZD1222) (Fig. 2A), an adenoviral vector vaccine was developed by the University of Oxford in the UK and the Sweden-based pharmaceutical company AstraZeneca plc (42).

Sputnik V. Sputnik V (previously Gam-COVID-Vac), manufactured by Gamaleya, was created by using two different adenoviral vectors: Recombinant Ad26 (rAd26) and Ad5, both carrying the spike gene. The two different adenoviral vectors were chosen to avoid a possible immunity of the vector after the first dose. In the phase I/II trial, 76 healthy adult volunteers (age, 18-60 years) were enrolled and received the dose of $10^{11}$ viral particles $\mathrm{rAd} 26-\mathrm{S}$ per dose on day 0 and the dose of rAd5-S on day 21. After 42 days, NAb levels resulted in $\sim 49.25$ GMT and a seroconversion rate of $\sim 100 \%$. All reported adverse events were mild and not serious. Furthermore, the $\mathrm{NAb}$ titer was similar to those of convalescent plasma from patients with COVID-19 (43).

Ad26.COV2.S. Ad26.COV2.S (Fig. 2B) is a vaccine based on the Ad26-vector developed by the Belgian company Janssen Pharmaceuticals, Inc. under the American medical company Johnson \& Johnson. The vector contains the spike gene with the addition of a gene encoding tissue plasminogen activator as an adjuvant. A significant humoral and cellular immunogenicity was reported in mice and macaques in pre-clinical studies for fused and stabilized S immunogen (S-2P) (44).

Ad5-nCoV. Ad5-nCoV manufactured by the Beijing Institute of Biotechnology and CanSino Biologics in China, was established using Ad5 vectors expressing the full-length spike DNA (Table I). In the phase II trial, 116,603 healthy participants (aged $\geq 18$ years) were recruited and received the vaccine at two different concentrations (dose of $1 \times 10^{11}$ or $5 \times 10^{10}$ viral particles per $\mathrm{ml}$ ), or a placebo (45). The participants received a single shot since a booster vaccination was non-beneficial for the Ad5 vector. Furthermore, significant NAbs responses were induced by both concentrations with GMTs of 19.5 and 18.3, for doses $1 \times 10^{11}$ or $5 \times 10^{10}$ respectively. After 28 days, seroconversion rates were 96 and 97\%, respectively. Moreover, both doses were able to induce a strong T cell response of $\sim 90$ and $88 \%$, as shown by IFN- $\gamma$ ELISA results. It was found that the reactogenicity was mild to moderate. However, a second dose was advised (between months 3 and 6) to improve immune endurance (45).

mRNA-based SARSCoV-2 vaccines. At present, the two mRNA-based SARS-CoV-2 vaccines, mRNA-1273 and BNT162b1, have been designed and developed by Moderna, Inc. (with support from the USA National Institute of Allergy and Infectious Diseases) and by the German biotech company BioNTech SE (in collaboration with the US-based pharmaceutical giant Pfizer, Inc.), respectively.

mRNA-1273 can translate the full-length spike protein, which contains a transmembrane anchor and an intact S1-S2 cleavage site, and two modified prolines $\mathrm{S} 2$ (S-2P). Furthermore, it can induce increased NAb levels and $\mathrm{T}$ cell responses in mice against both wild-type and the D614G mutant virus, in addition to $\mathrm{T}$ cell-SARS-CoV-2 immune responses, as shown in phase I/II/III clinical trials (46).

The other mRNA vaccine, BNT162b1, can translate the RBD of the SARS-CoV-2 spike protein, which plays a crucial role in virus-NAbs (47). Furthermore, a Foldon trimerization motif was added to the end of the RBD sequence to improve the immunogenicity effect, while the mRNA sequence was modified to increase it's in vivo translation $(48,49)$ (Table I; Fig. 3A and B).

\section{Efficacy and adverse events of COVID-19 vaccines}

AZD1222 vaccine (AstraZeneca or Vaxzevria). The AZD1222 vaccine (AstraZeneca plc) has been shown to induce a high 

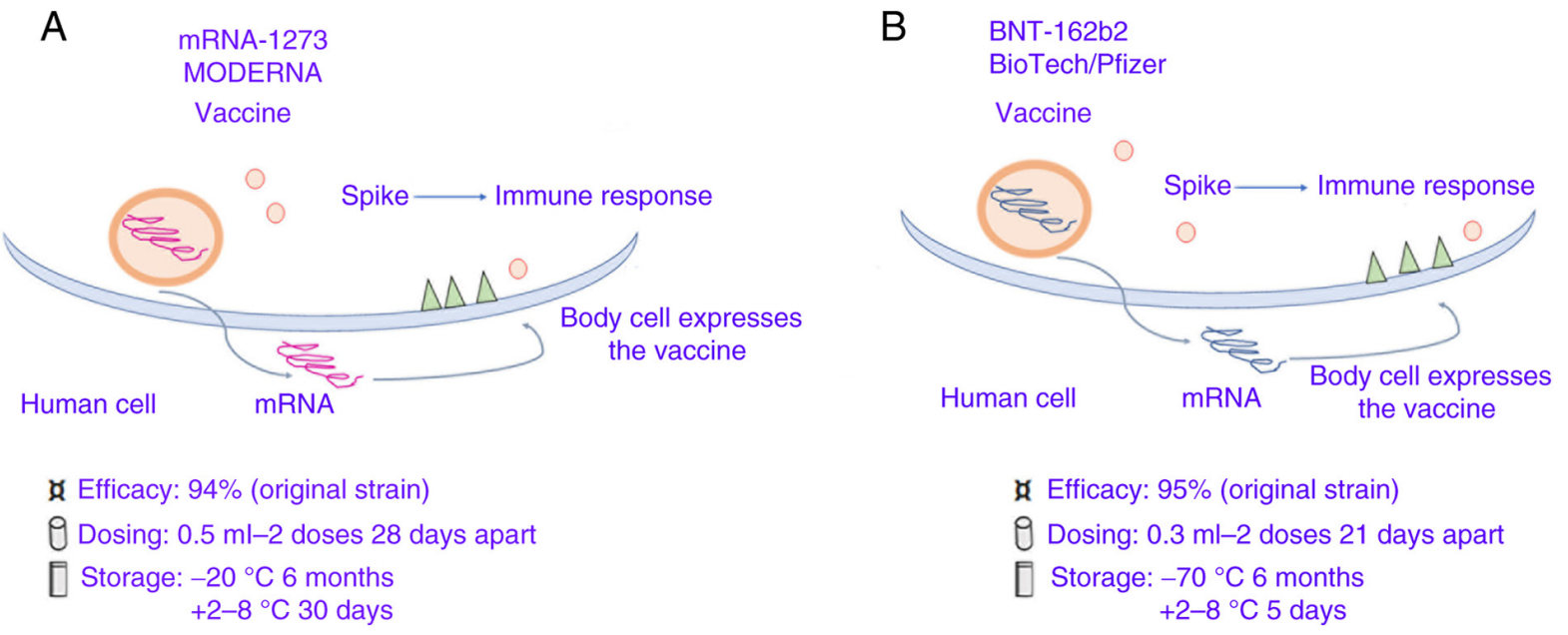

Figure 3. Coronavirus-19 vaccines based on spike protein mRNA carried by lipidic microparticles. (A) Moderna/mRNA-1273. (B) BioNTech/Fosun/Pfizer BNT162b1.

antibody response in swine models (50). In a randomized, single-blinded trial phase I/II trial, 1,077 healthy participants (aged 18-55 years) were enrolled (51). All participants were divided into two arms: i) The first arm received the AZD1222 vaccine at a dose of $5 \times 10^{10}$ vaccine particles $(n=543)$; and ii) the second arm received a placebo with the meningococcal vaccine, MenACWY ( $n=534)$ (51). The dose for the AZD1222 vaccine was based on the Oxford group's experience with a similar type of ChAdOx1 vaccine for MERS (51). In the AZD1222 group, 10 participants were chosen to receive a second dose of the vaccine after 28 days from the first dose (51).

In an ongoing clinical study registered at ISRCTN (15281137) and ClinicalTrials.gov (NCT04324606), participants in the ChAdOx1 nCoV-19 group received two doses containing $5 \times 10^{10}$ viral particles (standard dose; SD/SD cohort); while a subset in the UK trial received a half dose as their first dose (low dose) and a standard dose as their second dose. Moreover, the participants of this study were also separated in two groups: i) 56 of 543 participants of the first arm did not receive paracetamol; and ii) 57 of 534 participants of the second arm received paracetamol (51). The investigators found that the local and systemic adverse events were lower in the paracetamol group compared with the control group (no paracetamol) (51). The same result was also obtained in the placebo groups. Moreover, the participants, who were given paracetamol, had reduced pain, tenderness, fatigue and headaches when compared with the non-paracetamol prophylactic group (51). The group treated with paracetamol also presented with fewer adverse events such as myalgia, chills and fever (51). These events were considered as mild or moderate, but they could become severe a day after vaccination. However, the authors also reported that neutropenia was found in $46 \%$ of the participants in the vaccine group in comparison with $7 \%$ of the control MenACWY group. In addition, high specific antibodies levels were detected in the vaccine group after 28 days, and until day 56. The levels these antibodies were higher in the 10 participants who received a booster shot by day 56 . After the second dose, $91 \%$ of participants in the vaccine group had a high NAb response. All participants showed an elevated T cell response at 14 days, and until day 56. However, such response did not increase in the participants after the second dose. This phase I/II trial study had some limitations, such as the small sample size $(n=10)$ in the booster group (51).

To assess the safety and immune response, another phase I/II trial was performed, involving 2,000 participants with or without HIV in South Africa (aged 18-65 years), who were divided into different groups based on different doses of the vaccine or placebo (52). The phase III/IV trial included $>30,000$ healthy volunteers in the United States, Brazil, South Africa and India $(53,54)$. In Brazil, 2,000 participants were divided into two groups: i) A vaccine group that received

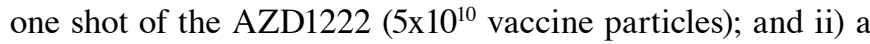
control group that received $0.5 \mathrm{ml}$ meningococcal MenACWY vaccine (53). Furthermore, paracetamol was administrated to volunteers for 1 day after the vaccination (53). Additionally, the other 30,000 volunteers, recruited across the United States, were split into two arms: i) One arm received two doses of the AZD1222 vaccine $\left(5 \times 10^{10}\right.$ vaccine particles and the second dose after 4 weeks); ii) the second arm received two doses of a saline placebo $(54,55)$. The results demonstrated that the vaccine was effective in $\sim 62.1 \%$ of participants who received two standard doses, while the efficacy of the vaccine reached $\sim 90 \%$ in the participants who received the first dose at low concentration, followed by the second dose at standard concentration $(54,55)$. Furthermore, 74,341 individuals were followed up for different time periods (median, 3.4 months; interquartile range 1.3-4.8). A total of 84 severe adverse events were described in the vaccine group and 91 in the control group, for a total of 168 participants. In total, three events were considered as possibly linked to the vaccine administration: One in the vaccine group, one in the control group and one participant who had no group allocation $(54,55)$.

Using vaccine sera, another study showed that NAb levels were reduced by $\sim 12.4$-fold for the South African variant (B.1.351) (56). Furthermore, another study indicated that the vaccine against this South African variant was effective $(\sim 10.4 \%)$ after the second dose for mild to moderate COVID-19 in 1,500 HIV-negative young adults (57). It has also been demonstrated that antibodies levels were 2.9-fold lower against the Brazilian variant (P1) when using vaccine sera (58). 
Data obtained by the UK vaccination program published on 17 March 2021 (59) suggested that the vaccine effectiveness was $\sim 56 \%$ in individuals aged $\geq 70$ years between $28-34$ days post-vaccination and it increased to $\sim 58 \%$ from day 35 onwards. In addition, results from a previous study proposed that this vaccine could reduce transmission by $67 \%$ (51). Another study performed by Public Health Scotland and the University of Glasgow (60) examined 150,000 healthcare workers with or without vaccination, along with 200,000 of their household members (60). The authors reported a $30 \%$ reduction in documented cases of infection in household members of vaccinated healthcare workers compared with unvaccinated healthcare workers. Furthermore, it was demonstrated that this reduction in transmission could be $\sim 60 \%$, considering other infection routes for the household members (60). Numerous different adverse reactions were described such as injection site tenderness $(63.7 \%)$, injection site pain $(54.2 \%)$, headache (52.6\%), fatigue (53.1\%), myalgia (44.0\%), malaise $(44.2 \%)$, pyrexia [includes feverishness $(33.6 \%)$ and fever $>38^{\circ} \mathrm{C}$ (7.9\%)], chills (31.9\%), arthralgia (26.4\%) and nausea (21.9\%). The incidence of adverse reactions in individuals with $\geq 1$ local or systemic event after any vaccination was high on day 1 following vaccination, while this incidence was reduced to 4 and $13 \%$, respectively, after day 7 . The most common systemic adverse events were fatigue, headache and malaise after 7 days. Moreover, a few neuroinflammatory events were observed after vaccination, but it was difficult to identify a causal relationship. In total, three cases of facial paralysis were described in the vaccine group and three in the control group. In the vaccine group, three cases of all one-sided 'facial nerve palsies' were described, but two of them could be not associated with vaccination, while one case could be associated with chronic suppurative otitis media/mastoiditis and this other occurred 80 days after vaccination. 'Neuroinflammatory conditions' were reported in the risk management plan as a significant potential risk and are important to monitor using routine pharmacovigilance activities. Moreover, the investigators observed five serious adverse events: Two in the vaccine group (pyrexia and transverse myelitis) and three in the control group (autoimmune hemolytic anemia, C-reactive protein increased and myelitis).

On 29 January 2021, the European Medicines Agency (EMA) recommended that the COVID-19 vaccine AstraZeneca was authorized across the EU. In addition, the UK government has provided data on the adverse events of Oxford/AstraZeneca vaccine administration between 4/01/2021 and 28/02/2021 (61). During March 2021, a previous study reported that participants were strongly positive for anti-platelet antibodies, as determined using immunoassays. In total, 11 patients [9 women and 2 men; median age, 36 (age range, 22-49)] presented thrombosis between 4-16 days post-vaccination; 1 patient presented with fatal intracranial hemorrhage and six patients died (62). Heparin was not administrated to the patients before symptom onset. In addition, 4 patients had high levels of anti-PF4/heparin antibodies and an elevated platelet activation assay in the presence of PF4, independent of heparin. Furthermore, high concentrations of heparin, Fc receptor-blocking monoclonal antibody and intravenous immunoglobulin were able to block platelet activation (62). The authors concluded that this AZD1222 vaccine could induce a prothrombotic disorder that clinically was very similar to heparin-induced thrombocytopenia with a different serological profile (62). In the same study, the authors investigated the mechanism for early post-vaccine inflammatory reactions as a potential co-stimulant for anti-platelet factor 4 (anti-PF4) immune response, evaluating vaccine-induced immune thrombotic thrombocytopenia (VITT) antibodies for inducing the release of procoagulant DNA-containing neutrophil extracellular traps (NETs), as well as measuring DNase activity in VITT patient serum. It was found that PF4 could bind to vaccine constituents (such as virus proteins) to form multimolecular complexes that were recognized by VITT antibodies, as determined using biophysical analyses (62). Furthermore, EDTA, another vaccine constituent, can increase microvascular leakage in mice to allow circulation of virus- and virus-producing cell culture-derived proteins. For this reason, antibodies in normal sera could cross-react with human proteins of the vaccine by inducing inflammatory reactions that were observed in individual after ChAdOx1-Cov-19 vaccination. Moreover, polyphosphates and DNA can trigger PF4-dependent platelet activation by VITT antibodies. In the presence of platelets, PF4 can trigger VITT antibody-driven procoagulant NETs formation, while DNase activity in VITT sera, with granulocyte-rich cerebral vein thrombosis, was observed in 1 patient with VITT (62).

Other studies have reported very serious adverse effects in participants after AZD1222 vaccination (63-68). The Anglo-Swedish pharmaceutical company AstraZeneca plc and the British University of Oxford decided to change the name of the vaccine to 'Vaxzevria' (on 25 March 2021) and provided safety updates (formation of blood clots in the blood vessels). In this case, individuals after vaccination report symptoms such as shortness of breath, chest or persistent abdominal pain, leg swelling, severe or persistent headache, blurred vision, persistent bleeding, and skin bruising or round, pinpoint spots beyond the site of vaccination appearing after a few days. When symptoms of blood clotting occur and persist, individuals should receive immediate medical attention. In this regard, most European countries recommend this vaccine in individuals $\geq 60$ years of age. Moreover, Belgium decided that this vaccine will no longer be administered to individuals under the age of 56, while South Korea has set the threshold at 60 years of age. At present, it has been reported that some individuals do not show up to receive this vaccine, while others have refused it in the vaccination center. Currently, the EU has not yet placed any new orders for AstraZeneca vaccines beyond June 2021 when their current contract ends (69).

Janssen (Ad26.COV2.S). In a phase I/II trial study, the Ad26. COV2.S vaccine was administered either in a single dose or in two doses with a different number of viral particles $\left(5 \times 10^{10}\right.$ or $1 \times 10^{10}$ viral particles) and spaced by 56 days in healthy individuals who were $18-55$ years old (cohort 1a) and $\geq 65$ years (cohort 3). Furthermore, longer-term data were compared between single dose and two dose regimens (cohort 2). After a single dose, spike antibodies were found at $99 \%$ in cohort $1 \mathrm{a}$ and $100 \%$ in cohort 3 . After 14 post-vaccination, Th1 cytokine-producing, $\mathrm{S}$-specific $\mathrm{CD} 4^{+} \mathrm{T}$ cell responses were 80 and $83 \%$ in cohort 1 and 3 , respectively, while $\mathrm{CD}^{+}$ $\mathrm{T}$ cell responses were high in both cohorts $1 \mathrm{a}$ and 3 , for both 
doses (70). In a previous study COV3001 (phase III data for COVID-19 vaccine candidate Ad26.COV2.S), 39,321 participants were enrolled who were aged $\geq 18$ years old at baseline, and $20 \%$ of them were aged $18-40$ years old. Participants were randomly split into two groups; 19,630 SARS-CoV-2-negative patients received one dose of the Ad26.COV2.S vaccine, and 19,691 patients received a placebo. Furthermore, 8 weeks of follow-up after vaccination was performed in all participants to assess the efficacy and safety of the vaccine. The international study population included of $46.7 \%(n=18,356)$ Americans, $40.6 \%(n=15,981)$ residents of Latin America and $12.7 \%(n=4,984)$ residents of South Africa. After 14 days, the investigators observed 116 positive COVID-19 cases among vaccinated participants (vaccine efficacy at 66.9\%), and 348 positive cases in the placebo arm. In addition, in participants $>60$ years old, the vaccine was effective at $76.3 \%$. After 28 days, the investigators found 193 positive cases in the placebo arm and 66 positive COVID-19 cases (with no previous SARS-CoV-2 history) in vaccinated participants, with a vaccine efficacy of $66.1 \%$ among younger and older participants (71). Moreover, the investigators observed that the vaccine was effective at $74.4 \%$ after 14 days and $72.0 \%$ after 28 days in American participants, while its efficacy was at $52 \%$ after 14 days and $64 \%$ after 28 days in South African participants (71). The results demonstrated that its efficacy was 52.0 and $64.0 \%$ in 86 moderate COVID-19 cases with the South Africa variant (sequenced virus having the 20H/501Y.V2 variant), with onset of disease $\geq 14$ and $\geq 28$ days after vaccination, respectively. The efficacy of the vaccine against the severe-critical COVID-19 cases with South Africa variant increased to 73.1 and $81.7 \%$, with an onset of disease $\geq 14$ and $\geq 28$ days post-vaccination, respectively (71). The investigators reported high reactogenicity in the Ad26.COV2.S group compared with the placebo group. The serious adverse events rate was similar between the two groups: Three deaths occurred in the vaccine group (none were COVID-19 related), and 16 in the placebo group (five were COVID-19 related) (71). In summary, these data suggest that one dose of Ad26.COV2.S can protect against symptomatic and asymptomatic SARS-CoV-2 infection, as well as against severe-critical disease.

There have been a few studies examining this vaccine in different COVID variants. The results submitted to the United States Food and Drug Administration (FDA) on the Brazilian variant suggest that Ad26.COV2.S had an efficacy of $68.1 \%$ against moderate and severe disease (71). A small-sample preprint study (has not been peer reviewed) reported that this vaccine produced a high level of neutralizing antibody activity against the Delta variant (72). The adverse events induced by this vaccine are injection site pain $(48.6 \%)$, headache $(38.9 \%)$, fatigue $(38.2 \%)$ and myalgia $(33.2 \%)(52,65)$. Investigators have observed non-serious urticaria events among vaccinated participants $(n=5)$ vs. placebo $(n=1)$ within 7 days post-vaccination, as well as imbalances in thromboembolic events (15 vs. 10) and tinnitus (6 vs. 0) (73). Furthermore, the FDA reported 15 cases of 'embolic and thrombotic events' or blood clots among 14 recipients in the vaccine group, compared with 10 in the placebo group (74).

A recent study reported 12 cases of cerebral venous sinus thrombosis (CVST) with thrombocytopenia following the use of the Ad26.COV2.S vaccine in patients (white women aged from 18-60 years) (75). In addition, 7 patients had $\geq 1$ CVST risk factor, including obesity, hypothyroidism and oral contraceptive use; none had received heparin. After Ad26.COV2.S vaccination, symptom onset can occur from 6-15 days. It was identified that 11 patients had a headache, and 1 patient initially had back pain and later developed a headache. Among the 12 patients with CVST, 7 reported intracerebral hemorrhage, and 8 had non-CVST thromboses. After a diagnosis of CVST, 6 patients initially were treated with heparin and platelet nadir was measured in a range from $9 \times 10^{3}-127 \times 10^{3} / \mu 1$. The heparin-PF4 antibody was detected in 11 patients through ELISA screening. All patients were hospitalized (10 in an ICU). At the end of April 2021, 3 patients were dead, 3 were treated in the ICU, 2 were hospitalized and 4 were discharged home (75). Most European countries have recommended this vaccine from 60 years of age.

Moderna/mRNA-1273. In the preclinical trials of the Moderna vaccine, mice were immunized with two different doses at 0.01 or $0.1 \mu \mathrm{g}$ (47). Another trial reported a high pseudo-virus NAb titer with the $1 \mu \mathrm{g}$ dose. Additionally, a high pseudo-virus NAb concentration was also found in mice expressing the mutated form of the spike protein, D614G(76). Furthermore, a significant cytotoxic $\mathrm{T}$ cell response was observed along with a balanced Th1/Th2 response after a $1 \mu \mathrm{g}$ dose in a mouse model (76). Thus, a $100 \mu \mathrm{g}$ dose was chosen in human trials, as a $1 \mu \mathrm{g}$ dose in animal models corresponds to a $100 \mu \mathrm{g}$ in humans (76). In phase I trials, 45 healthy participants, aged 18-55 years old, were recruited and divided into three groups of different doses $(25,100$ and $250 \mu \mathrm{g})(77)$. In total, two doses were administered intramuscularly 28 days apart. The data showed that a specific antibody response was apparent dependent on the dose concentration and peaked at day 15 after the first dose. NAbs were detected in $<1 / 2$ of the participants following the first vaccination, but NAbs were detected in all participants following the second vaccination (77). Furthermore, $\mathrm{CD} 4^{+} \mathrm{T}$ cell responses were observed in participants who received the 25 and $100 \mu \mathrm{g}$ doses (77).

The phase IIa trial conducted by Moderna, Inc. recruited 600 healthy participants aged $\geq 18$ years old (78). The participants were split into eight groups based on age and dose: i) Four groups of participants received 50 and $100 \mu \mathrm{g}$ doses of the Moderna vaccine; and ii) the other four groups of participants received 50 and $100 \mu \mathrm{g}$ saline (placebo) (78). Based on a published preliminary report, the interim results revealed that no serious adverse events were observed, but one participant did not receive the second $25 \mu \mathrm{g}$ dose after experiencing transient urticaria after the first dose (76). There was no fever observed after the first dose, however, some participants in the $100(6 / 15 ; 40 \%)$ and $250 \mu \mathrm{g}(8 / 14 ; 57 \%)$ groups reported fever after the second dose (76). Local adverse events such as pain at the injection site (grade 1 and 2), were described (76). In addition, other systemic and local adverse effects, including myalgia, headaches, fatigue and chills, were reported in different participants after both doses. In total, three individuals in the $250 \mu \mathrm{g}$ group (21\%) reported severe systemic adverse effects following the second dose (76).

The phase III COVE study enrolled 30,420 volunteers who were randomly assigned in 1:1 ratio to receive either vaccine or placebo (15,210 participants in each group). In total, $26 \%$ 
of participants received both injections, and $2.2 \%$ of participants were infected by SARS-CoV-2 as shown by serological and virological testing (79). In the placebo group, 185 cases of symptomatic COVID-19 were detected and only 11 cases in the mRNA-1273 vaccine group. The vaccine efficacy was $\sim 94.1 \%$ across key secondary analyses, including assessment 14 days after the first dose. Severe COVID-19 cases were reported in 30 participants in the placebo group, with one fatality. Moderate, transient reactogenicity after vaccination occurred more frequently in the mRNA-1273 vaccine group (79). Serious adverse events were rare, with the same incidence indicated in both groups (79).

Moderna, Inc. is currently conducting another trial on children aged 6 months to 12 years (KidCOVE). This phase II/III trial is separated into two parts: i) The first is an open-label, dose-escalation, age de-escalation phase; and ii) is followed by a randomized, observer-blind, placebo-controlled expansion. Both will examine the safety, tolerability, reactogenicity and effectiveness of the two-dose vaccine, which will be given 28 days apart in the first part of the trial. Participants aged 2-12 years will receive the first dose of the mRNA vaccine at 50 or $100 \mu \mathrm{g}$. Those aged between 6 months and 2 years will receive the first of three doses at either 25,50 or $100 \mu \mathrm{g}$. Following administration, an interim analysis will assess what dose is given in the second part of the trial. Following the administration of the second dose of the vaccine, all participants will be followed up for 12 months. Effectiveness will be determined through either achieving a correlate of protection or through 'immunobridging' the population aged 18-25 years, according to Moderna, Inc. (80).

Other studies have shown that Moderna vaccine was able to generate NAbs against the B.1.351 S variant with a reduced 5- to 10-fold response in comparison with pseudovirus bearing the D614G mutation (81-83). However, further studies are necessary to evaluate the efficacy of the second dose in individuals infected by this variant. Moreover, clinical trials have reported that the vaccine was effective at $86.4 \%$ in symptomatic infections at 14 days after the second dose in individual aged $>65$ years (84). Results submitted to the USA FDA by Moderna, Inc. from a clinical trial on swabs derived from individuals with asymptomatic infections have shown that transmission could decrease by $2 / 3$ after one dose, though the number of people with asymptomatic infections was small (85). Another observational study in the US, published on 29 March 2021, found that both asymptomatic and symptomatic infections decreased by $\sim 90 \%$ at 14 days after the second dose (79). The Moderna vaccine can induce common adverse effects such as pain or swelling at the injection site, headache, nausea, vomiting muscle ache, joint aches and stiffness, tiredness, chills and fever, while severe allergic reactions are rare, such as difficulty breathing, swelling of the face and throat, fast heartbeat, bodily rash, dizziness and weakness (86).

BioNTech/Fosun/Pfizer BNT162b1. During the phase I trial, the BioNTech/Pfizer vaccine (BNT162b1) was tested on 195 healthy volunteers in the USA (aged, 18-55 years) who were divided into 13 different groups with 15 participants. In each group, 12 participants received the vaccine at different doses $(10,30$ and $100 \mu \mathrm{g})$ and 3 participants in each group received a placebo (87). The doses of 10 and $30 \mu \mathrm{g}$ were administered intramuscularly 20 days apart; while in the group with $100 \mu \mathrm{g}$, the participants received one dose (87). Based on interim data, participants had increased IgG levels within 7 days after the second dose, until 14 days after (87). The participants of the $100 \mu \mathrm{g}$ dose group showed a high peak of IgG levels at 21 days after the first dose and these did not increase thereafter (87). Furthermore, the results of this trial reported that there was no significant difference in the immune response in participants of the 30 and $100 \mu \mathrm{g}$ groups after the first dose (87). For this reason, the investigators choose the 10 and $30 \mu \mathrm{g}$ doses to proceed through future trials (87).

In another random clinical trial, a total of 43,448 participants were divided into two arms: i) One arm of 21,720 participants who received BNT162b2 vaccine; and ii) one arm of 21,728 participants who received placebo (88). In total, 8 cases of COVID-19 were detected $\geq 7$ days after the second dose in the BNT162b2 arm, while there were 162 cases in the placebo arm. The BNT162b2 vaccine was $95 \%$ effective against COVID-19. Moreover, the authors found that the vaccine efficacy was between $90-100 \%$ in the different subgroups (age, sex, ethnicity, baseline BMI and the presence of co-existing conditions). In the BNT162b2 arm, 10 cases of severe COVID-19 were detected after the first dose, while 9 cases were observed in the placebo arm (88). The most common side effects of the BNT162b2 vaccine were mild-to-moderate pain at the injection site, fatigue and headache in the short term. The serious adverse events were very low, with the same incidence between the vaccine and placebo arms (88).

Laboratory findings (89), results from the UK vaccination program (90) and the PHE SIREN study (91) indicated that the BNT162b1 vaccine was effective against the UK variant (B.1.1.7). Another laboratory study revealed that NAb levels decreased 10.3-fold against the South African variant (B.1.351) (56). Moreover, Pfizer/BioNTech's phase III trial, conducted in 800 participants, reported 9 cases of COVID-19 in the placebo group (6 were due to B.1.351), while no cases were observed in the vaccine group, and for this reason, the investigators confirmed the high vaccine efficacy (100\%) against the variants (announced 1 April 2021) (92). Moreover, two laboratory studies showed that antibody levels were decreased by 2.6- and 1.4-fold against the Brazilian variant (P1) $(93,94)$.

A recent study examined whether NAb levels could increase against the B.1.1.7, B.1.351 and P.1 variants after one dose of the BNT162b2 vaccine in individuals who were previously infected with SARS-CoV-2 (95). This study isolated the original virus (sublineage B.1) and the B.1.1.7, B.1.351 and P.1 variants derived from 18 serum samples of 6 healthcare workers previously infected with SARS-CoV-2 (sublineage B.1) using a microneutralization assay (96). The samples were isolated from each patient at different time points, from 1-12 weeks after infection and before vaccination, and then from 1-2 weeks after vaccination. The authors found that NAbs were present against the original virus, as well as the B.1.1.7 and P.1 variants in the samples after the first time point, while they were not present against the B.1.351 variant. At the second time point, the samples had NAbs against the original virus, and the B.1.1.7, P.1 and B.1.351 variants (geometric mean titers were 81, 40, 36 and 7, respectively). Moreover, high NAb levels 
against the original virus and the B.1.1.7, P.1 and B.1.351 variants were found in samples at the third time point, and these levels after vaccination were 114, 203,81 and 228 times higher in comparison with those before vaccination. This study found that one vaccine dose increased NAb levels against all variants tested. The limitation of this study was due to the small cohort involving only women and the lack of evaluation of $\mathrm{T}$ cell response (95).

Another study reported two COVID-19 cases (two women) in a cohort of 417 individuals who had received the second dose of BNT162b2 (Pfizer/BioNTech) or mRNA-1273 (Moderna) vaccine $\geq 2$ weeks previously (96). Both cases had a positive result for SARS-CoV-2 after PCR testing. Specifically, one woman had a E484K mutant, while three mutations (T95I, del142-144 and D614G) were present in the other woman. Viral sequencing revealed variant E484K in one woman and three mutations (T95I, del142-144 and D614G) in the other women (96). These results indicate a potential risk of illness after successful vaccination and subsequent infection with variants of the virus. In another study, Geers et al (97) revealed that 23 healthcare workers, mildly infected by COVID-19 and then vaccinated with one dose of BNT162b2, had high levels of SARS-CoV-2-specific functional antibodies and virus-specific T cells. Furthermore, the authors observed that COVID-19-negative healthcare workers after one vaccine dose had specific immune responses that were strongly increased after the second dose. In addition, the vaccine produced both NAbs and Fc-mediated antibody effector functions $\mathrm{c}$ against the variants B.1.1.7 and B.1.351, with a lower efficacy of $\sim 2$ - to 4-fold with respect to the homologous virus. In addition, these authors stimulated peripheral blood mononuclear cells using peptide pools spanning the mutated $\mathrm{S}$ regions of B.1.1.7 and B.1.351, and it was found T cells that reacted with SARS-CoV-2-variants. Specifically, they reported no differences in $\mathrm{CD}^{+}{ }^{+} \mathrm{T}$ cell activation against variant antigens. These authors concluded that these variants could not escape $\mathrm{T}$ cell-mediated immunity induced by SARS-CoV-2 infection or BNT162b2 vaccination (98). However, further studies are required to evaluate the effects of a second vaccine dose on $\mathrm{NAb}$ levels against variants in previously infected individuals.

Results from the UK vaccination program indicated that the vaccine was effective at $58 \%$ in individuals aged $\geq 70$ years, and it reached $58 \%$ (from 28 days after vaccination) before plateauing (98). After one dose, the risk of emergency hospitalization and morality was reduced by $\sim 22$ and $54 \%$, respectively (98). Another study revealed that the vaccine was effective at 59\% from 28-34 days after the first dose in individuals aged $\geq 80$ years, and its efficacy reached up to $85 \%$ from 14 days after the second dose (89). Results from an Israeli study suggested that individuals can be infected after $\sim 12$ days or longer post-vaccination with reduced viral loads, which can affect viral shedding and contagiousness, as well as the severity of the disease (99). An observational study, conducted on 7,000 vaccinated healthcare workers in Israel, reported that both symptomatic and asymptomatic COVID-19 cases were decreased by $75 \%$, suggesting a reduction of viral transmission (100). Furthermore, other data announced by the Israel Ministry of Health on 15 March 2021 demonstrated that the vaccine was effective at $\sim 94 \%$ against asymptomatic infections 2 weeks after the second dose (101). The SIREN study, conducted among healthcare workers in England, showed that the vaccine was effective at $72 \%$ after one dose and $86 \%$ after two doses against all infections (91). Another study, carried out by healthcare workers of Cambridge University Hospitals NHS Foundation Trust, found that the risk of asymptomatic infection was reduced 4-fold in healthcare workers after 12 days post-vaccination, compared with unvaccinated healthcare workers (102).

A common event was pain at the injection site, which was mild or moderate, except for one severe event in the $100 \mu \mathrm{g}$ group (49). Other common systemic events, such as fatigue, headache, chills, muscle and joint aches, could become more serious after the second dose, but can be resolved within a day (49). After the first and second doses, some individuals experienced a fever that was resolved within 1 day (49). No grade 4 adverse events were described. However, some participants reported pyrexia and sleep disturbance (grade 3 events). In addition, lymphocyte and neutrophil counts in some participants were decreased, but these returned to normal after 6-8 days post-vaccination (49).

In a phase trial I/II/III, younger vaccine recipients (16-55 years of age) showed more systemic events compared with older vaccine recipients ( $>55$ years of age) after the second dose (88). The common systemic events included fatigue (59\%) and headache (52\%) (after the second dose) among younger vaccine recipients, and these were at 51 and $39 \%$ among older recipients (after the second dose). The incidence of any severe systemic event was $0.9 \%$ after the first dose and $2 \%$ after the second dose within each age group. In total, $16 \%$ of younger vaccine recipients and $11 \%$ of older recipients reported fever (temperature, $\geq 38^{\circ} \mathrm{C}$ ) after the first dose (88). A total of two participants in each group reported temperatures $>40.0^{\circ} \mathrm{C}$. Furthermore, younger vaccine recipients used more antipyretic or pain medication (28\% after dose $1 ; 45 \%$ after dose 2) compared with older vaccine recipients $(20 \%$ after dose 1; $38 \%$ after dose 2), while this type of medications was less frequently used among placebo recipients (10-14\%) compared with vaccine recipients (69-58\%). Lymphadenopathy was observed in both groups, including 64 participants in the vaccine group $(0.3 \%)$ and 6 in the placebo group $(<0.1 \%)(88)$. Additionally, some participants of the vaccine group reported shoulder injury associated with vaccine administration, as well as right axillary lymphadenopathy, paroxysmal ventricular arrhythmia and right leg paresthesia (88). In total, two participants in the vaccine group died (one from arteriosclerosis and one from cardiac arrest), as did four placebo recipients (two from unknown causes, one from hemorrhagic stroke and one from myocardial infarction) (88). No deaths were associated with the vaccine or placebo. Subsequent safety monitoring of participants will continue for 2 years after the second dose administration.

The UK government provided data on adverse events of Pzifer/BioNTech vaccine administration between 4/01/21-28/02/21, such as blood, cardiac, congenital, ear, endocrine, eye, gastrointestinal, hepatic and immune system disorders and infections (103). Another study analyzed results derived from the Centers for Disease Control and Prevention program known as ' $\mathrm{V}$-safe' $(>3,600,000$ individuals were enrolled before their first dose of a mRNA-based COVID-19 vaccine on February 21st, 2021). In total, $70 \%$ of individuals 
reported different adverse effects, such as injection site reaction, including pain or swelling, and 50\% had fatigue or chills (104). In another study, $73 \%$ of individuals who received the Moderna vaccine complained of one side effect compared with $65 \%$ of those who received a Pfizer/BioNTech vaccine. Moreover, $51 \%$ of Moderna recipients had full-body symptoms, in comparison with $48 \%$ of Pfizer/BioNTech recipients (105). In addition, $\sim 82 \%$ of individuals who received their second Moderna dose complained of injection site pain, compared with $69 \%$ of those vaccinated with Pfizer/BioNTech (105). Overall, 74\% of individuals vaccinated with Moderna reported different side effects compared with $64 \%$ of Pfizer/BioNTech recipients. It was observed that $40 \%$ of Moderna recipients had chills in comparison with $22 \%$ of the Pfizer/BioNTech recipients (105).

It has been reported that patients with COVID-19 present secondary immune thrombocytopenia (ITP) (106) and coagulopathy, which have contributed to a high mortality. Besides SARS-CoV-2, numerous other pathogens, such as Helicobacter pylori, H3N2 influenza virus and Dengue virus, can induce ITP $(107,108)$. In this regard, authors have proposed that the antibodies produced by the body to kill a virus present a potential cross-reactivity with surface antigens on platelets or megakaryocytes. Antibodies linked to platelets and megakaryocytes undergo reticuloendothelial phagocytosis and direct lysis by cytotoxic T cells, thereby leading to thrombocytopenia (107,108). Platelets, which are anucleate cells, can translate mRNA and synthesize proteins (107). RNA viruses can infect platelets in which mRNA can be translated, and this mechanism can cause an autoimmune response against platelets. For example, this mechanism can cause thrombocytopenia in patients affected by dengue fever. Furthermore, patients can have a significantly selective immune response against infected platelets or megakaryocytes after recovering from thrombocytopenia. In some patients infected by dengue virus, their immune response could provoke ITP and consequent subarachnoid, intracerebral or other internal hemorrhages, with a fatal outcome (107). In this context, it is possible to suggest that spike mRNAs in genetic COVID-19 vaccines may directly enter into platelets and megakaryocytes, and they are subsequently translated into spike protein at the intracellular level. Through this method it is possible to trigger an autoimmune response against platelets and megakaryocytes, ultimately including reticuloendothelial phagocytosis and direct $\mathrm{CD}^{+} \mathrm{T}$ cell lysis. Several thrombocytopenia cases after COVID-19 vaccination have been reported in the pharmacovigilance databases of the Vaccine Adverse Event Reporting System (VAERS) (109) and Medicines and Healthcare Products Regulatory Agency (UK) (109). ITP has also been described for other vaccines, such as those for flu, poliomyelitis, pneumococcal, hepatitis, MMR and rabies (110). Investigators have proposed vaccine-mediated autoimmunity in association with both the antigen and vaccine constituents (110). It was suggested that mRNA vaccines against COVID-19 may play a crucial role in triggering an autoimmune response against platelets that may clinically manifest in thrombocytopenia, hemorrhage and blood clots. The EMA continues to examine the recent thrombotic events (111).

Between 14 December 2020 and February 28 2021, a CDC v-safe COVID-19 Pregnancy trial was carried out on 35,691 v-safe pregnant participants (aged 16-54 years) who were vaccinated with a mRNA vaccine (Pfizer/BNT162b1 or Moderna/mRNA-1273) (112). A higher number of injection-site pain was reported by pregnant women compared with non-pregnant women, whereas headache, myalgia, chills and fever were reported less frequently (113). Among participants, 827 were considered pregnant, but 115 (13.9\%) had undergone a pregnancy loss, while $712(86.1 \%)$ had a live birth (mostly among participants with vaccination in the third trimester). In this trial, different adverse neonatal events were reported such as preterm birth (in 9.4\%) and small size for gestational age (in 3.2\%). Furthermore, adverse pregnancy and neonatal events were similar between individuals vaccinated against COVID-19 (who had a completed pregnancy) and pregnant women before the COVID-19 pandemic. Preliminary data show the safety of the mRNA vaccine among vaccinated pregnant women. However, other longitudinal studies are required to further understand maternal, pregnancy and infant outcomes. In conclusion, knowledge regarding vaccines is important since they can play a crucial role in providing successful treatment strategies during a pandemic (113).

\section{Mass vaccination}

At least 47,915,768 people received their first vaccination, while 42,379,353 people received the second doses in United Kingdom on the 26th August 2021 (114). However, COVID-19 infections have increased in England, Wales, Northern Ireland and Scotland in the week ending 20th August 2021. The estimated percentage of the community population (those not in hospitals, care homes or other institutional settings) that had COVID-19 in this week was $1.39 \%$ ( 1 in 70 people) in England; $0.83 \%$ (1 in 120 people) in Wales; $2.36 \%$ (1 in 40 people) in Northern Ireland and $0.70 \%$ (1 in 140 people) in Scotland. In England, the percentage of people aged 17-24 years who tested positive increased, as well as those aged 50-69 years, while there was a decrease in positive cases in those aged 2-11 years, and those aged 25-34 years $(114,115)$.

Furthermore, two studies $(90,116)$, performed by the University of Oxford, the UK's ONS and the Department for Health and Social Care, evaluated data from the 'COVID-19 Infection Survey'. Specifically, the authors have analyzed $1,610,562$ test results from nose and throat swabs taken from 373,402 study participants between 1 December 2020 and 3 April 2021. The first study (90) reported a reduced infection rate after 21 days from a single dose of either Oxford/AstraZeneca or Pfizer/BioNTech vaccines, as the number of new cases decreased by $\sim 74 \%$ in symptomatic infections and $57 \%$ in asymptomatic infections. One dose of either of the two vaccines were similarly effective against the B.1.1.7 variant. Meanwhile, two doses of the Pfizer/BioNTech vaccine decreased $70 \%$ of asymptomatic infections and $90 \%$ symptomatic infections (90). The second study (113) estimated antibody levels after a single dose of either Oxford/AstraZeneca or Pfizer/BioNTech vaccines, and after two doses of the Pfizer/BioNTech vaccine, generally given 21-42 days apart. The researchers found that antibody levels were comparatively lower with a single dose of either vaccine, particularly at older ages. In addition, antibody levels 
were high after two doses of the Pfizer/BioNTech vaccine across all ages, and particularly in older individuals (116).

In another study, 596,618 infected individuals were divided into different groups depending on infections type: i) Documented SARS-CoV-2; ii) symptomatic COVID-19; iii) COVID-19-related hospitalization; iv) severe illness; and v) death (117). The authors considered the BNT162b2 mRNA efficacy from days 14-20 after the first dose and $\geq 7$ days after the second dose. The vaccine efficacy was estimated at $46 \%$ (first dose) and 92\% (second dose) for documented cases; 57 and $94 \%$ (first and second dose, respectively) for symptomatic COVID-19 cases; 74 and 87\% (first and second dose, respectively) for hospitalized cases; and 62 and $92 \%$ (first and second dose, respectively) for severe illness (117). Furthermore, the investigators reported that the vaccine effectiveness in specific subpopulations for documented infections was lower in infected individuals with different coexisting conditions compared with symptomatic COVID-19 cases (117). In conclusion, this study revealed that the BNT162b2 mRNA vaccine efficacy was in the range of 94-95\%.

In another study (118) conducted on 8,517 adults in England and Wales by University College London (Virus Watch project), which reported that $96.42 \%$ of individuals had developed antibodies between 28-34 days after the first vaccine dose, and this reached $99.08 \%$ between 7-14 days after the second dose. NAb levels were increased quickly after the first dose of the Pfizer vaccine compared with those after the first dose of AstraZeneca at 14-20 days, but the levels were similar for both vaccines after 4 weeks. Furthermore, the antibody level was higher in young individuals when compared with older populations. Moreover, antibody levels were low in patients with diabetes, cardiovascular disease or cancer, in particular with those with hematological rather than solid organ cancer, and those currently on immunosuppressive therapy after the first dose of both vaccines. The difference disappeared completely after the second dose in individuals across all ages, demographics and clinical groups (118).

At present, the highly contagious variant, also known as B.1.617.2 or Delta (identified in India in October 2020), has spread to 85 countries, including Great Britain and Israel, where the rate of vaccination among the population is very high $(119,120)$.

Public Health England estimates that full vaccination using Pfizer or AstraZeneca vaccines reduces the risk of symptomatic COVID-19 caused by the Delta variant by $79 \%$, compared with an $89 \%$ reduction with the Alpha variant (120). Protection against the Delta variant after a single dose is weaker $(35 \%)$ compared with Alpha (49\%). Vaccine effectiveness against hospitalization with COVID-19 is higher, according to UK data. For instance, it has been calculated that two vaccinations with the Pfizer or AstraZeneca vaccine decreased the risk of infection by $79 \%$, compared with an $89 \%$ reduction with the Alpha variant. Furthermore, two doses of Pfizer reduced hospitalization by $\sim 96 \%$, while this was $92 \%$ for AstraZeneca vaccines (89). An Israeli study reported that Pfizer vaccine effectiveness against the Delta variant was $\sim 64 \%$ after two doses, and it can protect against infections and prevent severe cases (121). Some studies suggest that different vaccine products can protect against symptomatic infection and severe outcomes caused by the Delta variants $(122,123)$. However, several health experts indicated that the effectiveness of the current vaccines decreases with time (123-127). Recent data provided from Israel's Health Ministry reported that the effectiveness of Pfizer-BioNTech vaccine has decreased $\sim 39 \%$ at preventing infections and $\sim 41 \%$ at preventing symptomatic infections caused by the Delta variant, down from early estimates of $64 \% 2$ weeks prior. These findings are in contrast with several other studies that have found only a slightly decrease in protection against infection and mild illness caused by the Delta variant (between 80-90\%).

A large number of the population in Great Britain was only fully vaccinated by mid-April 2021, while the majority of population in Israel was fully vaccinated by the end of January 2021. It is becoming clear that vaccine immunity begins to decrease after $\sim 6$ months. Preliminary data have shown that a third dose of the Pfizer/BioNTech (22UAy.DE) COVID-19 vaccine is $86 \%$ effective in individuals aged $>60$ years in Israel (128).

At the end of June 11th, 2021, the FDA added a warning regarding the Pfizer PFE.N/BioNTech 22UAy.DE and Moderna mRNA COVID-19 vaccines, indicating the rare risk of heart inflammation after their use. As of June, 11th 2021, the USA VAERS reported $\sim 1,200$ cases of myocarditis or pericarditis from $\sim 300$ million mRNA vaccine doses administered. The number of cases appeared to be higher in men in the week after the second vaccine dose. The Centers for Disease Control and Prevention reported 309 hospitalizations from heart inflammation in young men (under the age of 30) (129).

\section{Remaining questions regarding mRNA vaccines}

Undoubtedly the RNA vaccine is a new approach to protect against infectious diseases. Since this novel technology allows human cells to build a viral protein, or a fragment of it, that triggers an immune response inside the body. There are some questions regarding the mRNA vaccine. Specifically, the mRNA-1273 and BNT162b1 vaccines use mRNA that can transcribe one of the spike proteins that cover the outer surface of SARS-CoV-2. After the injection of the vaccine, mRNA can enter into human cells that read viral mRNA and follow its instructions, and in this way, they produce only the spike proteins. At this point, when spike proteins are expressed in human cells, they induce the immune system response to remove them (130). In this regard, the immune system of a vaccinated individual against SARS-CoV-2 can react when it is exposed to the virus and defend against the virus. Thus, it can be important to understand the following: i) How are BNT162b2 and mRNA-1273 vaccines prepared to assure stability?; ii) how are the vaccine components able to enter into the cells?; iii) how do proteins or sugars enter into the cells?; iv) how does the protein machinery bind to receptors and gain access into human cells?; v) it is possible that the mRNA-1723 and BNT162b2-complex cannot by itself be translated, and thus it remains unknown how the machinery associated with mRNA-1723 and BNT162b2 could interact with the different apparatus of cells?; vi) Once the spike protein (or at least part of it) is generated, how does it translocate outside of the cell? Could this occur via membrane-bound protein gates? It remains difficult to understand how a gate can recognize a 'viral' protein and allow it to pass. It is probable 
that this vaccine contains one sequence to code the necessary amino acids to open the gate; and vii) spike proteins can become a component of some cells, and thus, is it possible that the immune system is not able to recognize them as 'viral' proteins in the long term? (130).

Some studies have shown that mRNA is contained in very small lipid bilayer spheres called micelles. Generally, such micelles merge with cell membranes and then release mRNA into the cytosol $(131,132)$. In summary, after injection, micelles enter into the cells and use the cellular translation apparatus to encode the spike proteins, reaching peak levels at 24-48 h, and can last for 72-96 h. After this process, the spike proteins or protein fragments protrude from the cellular membrane and can be recognized by the immune system. When these cells die, spike proteins and protein fragments contained in their debris can be taken up by antigen-presenting cells. Then, cells can detect these fragments, activate the immune system and aid other immune cells to fight the infection via the production of antibodies through B cells. In the case of infection, antibodies can recognize coronavirus spikes, and subsequently destroy the virus. Moreover, the antigen-presenting cells can also activate the killer $\mathrm{T}$ cells that can identify and destroy any coronavirus-infected cells that display the spike protein fragments on their surfaces (133-135). The use of oligonucleotides in therapeutic contexts poses two problems. First, free RNAs can be digested by nuclease in plasma, and second, free RNAs can have difficulty gaining access into the intracellular compartment and translation machinery. In this regard, lipid nanoparticles composed of cationic lipids and other lipid components, such as neutral lipids, cholesterol, polyethylene glycol (PEG) and PEGylated lipids, are used to contain oligonucleotides in order to prevent their degradation in plasma and to allow their cellular uptake.

A previous study (136) performed in cynomolgus macaques using yellow fever (YF) prME mRNA vaccine as a model system revealed the spatiotemporal trafficking of mRNA vaccine after its administration. The mRNA was associated with lipid derivatives of natural amino sugars (137-139) and then labeled with an orthogonal dual positron emission tomography (PET)-near-infrared (IR) probe. The authors choose $64 \mathrm{Cu}$, a radioisotope with a half-life of $12.7 \mathrm{~h}$, to track the mRNA for 2 days following administration intramuscularly (i.m.) in the right quadriceps. This study monitored the first $28 \mathrm{~h}$ of mRNA trafficking dynamics with high spatiotemporal resolution using PET-CT. After $4 \mathrm{~h}$ post-injection, a substantial signal in draining lymph nodes (ipsilateral iliac, inguinal and para-aortic) was observed and it increased over the next $28 \mathrm{~h}$ by an average of $70 \%$ (136). Subsequently, the cell types involved in vaccine uptake at the injection site and in the draining lymphoid organs were identified using near-IR fluorescence, as shown by PET imaging, and flow cytometry. In addition, mRNA distribution and protein expression within tissues and cells were determined using confocal microscopy. During necropsy, stitched images of the whole lymph node (at $28 \mathrm{~h}$ post i.m. injection) showed that the mRNA was detected outside the $\mathrm{B}$ cell follicles, whereas YF prME antigen was found in the interior of the germinal centers.

Based on these findings it is possible to suggest the mechanism of mRNA COVID-19 vaccines: These lipid nanoparticles containing spike mRNA may be absorbed into cells at the injection site and into the draining lymph nodes in lymphatic tissue in the armpit below the site of injection, as well as the spleen and liver (after 1 or 2 days). The delivered mRNA interacts with the translation apparatus of cells to encode proteins that are transiently expressed by dendritic cells and subcapsular sinus macrophages. Then, these spike proteins of SARS-CoV-2 (bound to the cellular membrane) are recognized by immune cells as a foreign antigen. After this process, both T cells and B cells produce NAbs against the virus (136).

It is also important to report the inactive ingredients for both mRNA vaccines. The BNT162b2 vaccine contains different lipids, such as 4-hydroxybutyl(azanediyl)bis(hexane-6,1-diyl) bis(2-hexyldecanoate),[PEG]-2000-N,N-ditetradecylacetamide, 1,2-distearoyl-sn-glycero-3-phosphocholine and $0.2 \mathrm{mg}$ cholesterol, electrolytes, including potassium chloride, monobasic potassium phosphate, sodium chloride and dibasic sodium phosphate dihydrate, sugar (sucrose) and the diluent saline, which is added to the vaccine for administration. The mRNA-1273 vaccine contains: Lipid SM-102 (eptadecan-9-yl 8-((2-hydroxyethyl) (6-oxo-6-(undecyloxy) hexyl) amino) octanoate); cholesterol 1,2-distearoyl-sn-glycero-3-phosphocholine; 1,2-dimyristoyl-rac-glycero-3-methoxyPEG-2000 (PEG2000 DMG); tromethamol; tromethamol hydrochloride; acetic acid; sodium acetate trihydrate; sucrose; and water for injections. The presence of PEG2000 in the lipid nanoparticle vaccines is still under investigation since it can be a potential allergen, and thus, is undergoing safety screening and evaluation of rare immediate hypersensitivity (139-142). The aforementioned substances can be implicated in the mechanism of vaccine reactions, such as IgE-mediated allergy leading to anaphylaxis, or other mechanisms that will provoke mild or moderate symptoms (urticaria, flushing, rash). Several vaccines contain substances such as PEG2000, PS80 and PS20, but evidence of pre-existing or documented PEG anaphylaxis in individuals remains limited. In this regard, some reports have shown that biological drugs can cause anaphylaxis via a mechanism that is not fully understood (139-142). However, there are also other topics regarding COVID vaccination and transmission that require further examination (143-146).

COVID-transmission in vaccinated individuals. It has been reported that even after vaccination, individuals can still infect others (147). Immunization with COVID-19 vaccines provides the best protection within 2 weeks of being fully vaccinated. A person is considered fully vaccinated 2 weeks after receiving the second dose of Pfizer's or Moderna's vaccine or one dose of Johnson \& Johnson's. Furthermore, if a person tests positive for COVID-19 or becomes ill a few days later, they most likely were exposed to the virus before being fully vaccinated. There are reported cases of illness and/or exposure after the vaccines, but the complications of the disease for those not vaccinated are of a greater magnitude. Furthermore, a person can be positive for COVID-19 before being fully vaccinated or after the complete cycle of vaccination (148). There are reported cases of illness after the vaccines with fewer complications. Moreover, important conditions such as obesity, asthma, chronic lung disease, diabetes, serious heart conditions, chronic kidney disease, AIDS, cancer, malnutrition disease, autoimmune or inflammatory diseases exponentially increase the mortality 
risk of patients with SARS-CoV-2 (146) Researchers have considered whether COVID-19 vaccines reduce the seriousness of symptoms and the chances of complications in infected individuals. Generally, after vaccination a person is protected from disease, but not necessarily infection, and for this reason, they could be asymptomatic or present with a few symptoms (149).

Longevity of COVID-19 vaccine-induced immunity. At present, the exact duration of protection given by COVID-19 remains unknown and is under investigation. Currently, ongoing trials by Pfizer show that the two-dose vaccine is highly effective for 6 months, or longer. Moreover, significant levels of NAbs were detected in vaccinated individuals with two doses of the Moderna vaccine for 6 months (147). A recent study analyzed different compartments of circulating immune memory to SARS-CoV-2 in 254 COVID-19 cases, including 43 cases at 6 months after infection. It was observed that levels of IgG to the spike protein remained stable for $>6$ months. In addition, the number of spike-specific memory B cells was high for 6 months compared with that observed at 1 month after symptom onset, while the number of SARS-CoV-2-specific $\mathrm{CD}^{+} \mathrm{T}$ and $\mathrm{CD}^{+} \mathrm{T}$ cells decreased with a half-life of 3-5 months. Finally, it was found that memory B, CD4 ${ }^{+} \mathrm{T}$ and $\mathrm{CD} 8^{+} \mathrm{T}$ cells to SARS-CoV-2 had distinct kinetics (150).

Currently, it remains debated whether vaccinated individuals should continue to follow social distancing or if they should be free from restrictions. The USA Centers for Disease Control and Prevention has published some specific guidance, such as that it is important to wear masks and follow social distancing to slow its spread until herd immunity is reached (151).

\section{Conclusions}

Vaccination plays an important role in preventing the COVID-19 pandemic, but there are some doubts regarding vaccine effectiveness, as well as its opposition and implementation. Previous studies have reported mathematical models of COVID-19 dynamics and the impact of vaccination that can play an important role for public health planning (152-155). For example, a study used a model of a COVID-19 epidemic to predict the effectiveness of vaccination in the USA (156). This model has considered different factors such as asymptomatic and symptomatic infectiousness, reported and unreported cases data, and social measures implemented to decrease infection transmission. This model has demonstrated that subsiding of the epidemic depends on both the vaccination implementation and the scale of relaxation of social measures that reduce disease transmission (156). Another study used a predictive model on the effect of vaccination to forecast the infection dynamics in three countries, including India, Brazil and USA (157). It was found that the USA requires a larger number of vaccines to eliminate COVID-19 compared with India and Brazil due to its highest number of active cases (157). However, several unknown factors can influence modelling vaccination against SARS-CoV-2 at this stage. Furthermore, it remains unknown that these vaccines can be effective to stop the COVID-19 pandemic. It has been suggested that second-generation vaccine production will be required to to end the pandemic. Thus, countries must increase research regarding novel vaccines and therapies against this virus through international collaboration (158).

In conclusion, an ideal COVID-19 vaccine should induce high levels of NAbs and reduced levels of non-NAb to avoid ADE potential. Furthermore, it should trigger robust Th1 cell-based responses and low Th2 cell-based responses to decrease the enhanced respiratory disease potential, as well as maintain long-lasting immunological memory. Several vaccines have shown protection efficacy in large-scale clinical trials, such as BioNTech/Pfizer and Moderna. At present, more studies are necessary for the AstraZeneca vaccine in mouse and non-primate models to further ascertain the protection efficacy and to study different adverse events, such as blood clots, low platelets and hemorrhage. Moreover, additional studies on almost all vaccine candidates will be necessary to assess the duration and level of protective immunity towards this disease. In summary, an effective COVID-19 vaccine will be the first goal to control this virus, but there are even greater challenges ahead. For example, to overcome the current pandemic, COVID-19 vaccines should be distributed worldwide. Moreover, basic scientific data must be easily accessible to create vaccines based on innovative platforms. To develop new mRNA vaccines that target viruses or cancer, high levels of financial support both from private companies and the governments of several nations are necessary. In this regard, it is necessary to build a larger capacity for scientific research in developing countries.

\section{Acknowledgements}

Not applicable.

\section{Funding}

No funding was received.

\section{Availability of data and materials}

Not applicable.

\section{Authors' contributions}

GM and AKS wrote the manuscript. SP revised the manuscript. GM, AKS and SP confirm the authenticity of all the raw data. All authors have read and approved the final manuscript.

\section{Ethics approval and consent to participate}

Not applicable.

\section{Patient consent for publication}

Not applicable.

\section{Competing interests}

The authors declare that they have no competing interests. 


\section{References}

1. Huang C, Wang Y, Li X, Ren L, Zhao J, Hu Y, Zhang L, Fan G $\mathrm{Xu} \mathrm{J}, \mathrm{Gu} \mathrm{X}$, et al: Clinical features of patients infected with 2019 novel coronavirus in Wuhan, China. Lancet 395: 497-506, 2020.

2. World Health Organization (WHO): Novel Coronavirus (2019-nCoV). WHO, Geneva, 2020. https://www.who.int/emergencies/diseases/novel-coronavirus-2019. Accessed February 7, 2020.

3. World Health Organization (WHO): WHO Coronavirus (COVID-19) Dashboard. WHO, Geneva, 2021. https://covid19. who.int/. Accessed August 18, 2021.

4. Kuba K, Imai Y and Penninger JM: Multiple functions of angiotensin-converting enzyme 2 and its relevance in cardiovascular diseases. Circ J 77: 301-308, 2013.

5. Fukui K, Yang Q, Cao Y, Takahashi N, Hatakeyama H, Wang H, Wada J, Zhang Y, Marselli L, Nammo T, et al: The HNF-1 target Collectrin controls insulin exocytosis by SNARE complex formation. Cell Metab 2: 373-384, 2005.

6. Gallagher PE, Ferrario CM and Tallant EA: Regulation of ACE2 in cardiac myocytes and fibroblasts. Am J Physiol Heart Circ Physiol 295: H2373-H2379, 2008

7. Warner FJ, Lew RA, Smith AI, Lambert DW, Hooper NM and Turner AJ: Angiotensin-converting enzyme 2 (ACE2), but not ACE, is preferentially localized to the apical surface of polarized kidney cells. J Biol Chem 280: 39353-39362, 2005.

8. Tseng CT, Tseng J, Perrone L, Worthy M, Popov V and Peters CJ: Apical entry and release of severe acute respiratory syndrome-associated coronavirus in polarized Calu-3 lung epithelial cells. J Virol 79: 9470-9479, 2005.

9. Tai W, He L, Zhang X, Pu J, Voronin D, Jiang S, Zhou Y and Du L: Characterization of the receptor-binding domain (RBD) of 2019 novel coronavirus: Implication for development of RBD protein as a viral attachment inhibitor and vaccine. Cell Mol Immunol 17: 613-620, 2020.

10. Coutard B, Valle C, de Lamballerie X, Canard B, Seidah NG and Decroly E: The spike glycoprotein of the new coronavirus 2019-nCoV contains a furin-like cleavage site absent in $\mathrm{CoV}$ of the same clade. Antiviral Res 176: 104742, 2020.

11. Daniloski Z, Jordan TX, Ilmain JK, Guo X, Bhabha G, tenOever BR and Sanjana NE: The Spike D614G mutation increases SARS-CoV-2 infection of multiple human cell types. Elife 10: e65365, 2021.

12. Ortega MA, Fraile-Martínez O, García-Montero C, García-Gallego S, Sánchez-Trujillo L, Torres-Carranza D, Álvarez-Mon MÁ, Pekarek L, García-Honduvilla N, Bujan J, et al: An integrative look at SARS-CoV-2 (Review). Int J Mol Med 47: 415-434, 2021.

13. Kim SR, Nam SH and Kim YR: Risk factors on the progression to clinical outcomes of COVID-19 patients in South Korea: Using national data. Int J Environ Res Public Health 17: 8847, 2020 .

14. Tian J, Yuan X, Xiao J, Zhong Q, Yang C, Liu B, Cai Y, Lu Z, Wang J, Wang Y, et al: Clinical characteristics and risk factors associated with COVID-19 disease severity in patients with cancer in Wuhan, China: A multicentre, retrospective, cohort study. Lancet Oncol 21: 893-903, 2020.

15. Luo Y, Mao L, Yuan X, Xue Y, Lin Q, Tang G, Song H, Wang F and Sun Z: Prediction model based on the combination of cytokines and lymphocyte subsets for prognosis of SARS-CoV-2 infection. J Clin Immunol 40: 960-969, 2020.

16. Gong J, Ou J, Qiu X, Jie Y, Chen Y, Yuan L, Cao J, Tan M, Xu W, Zheng F, et al: A tool for early prediction of severe coronavirus disease 2019 (COVID-19): A multicenter study using the risk Nomogram in Wuhan and Guangdong, China. Clin Infect Dis 71: $833-840,2020$.

17. Ponti G, Maccaferri M, Ruini C, Tomasi A and Ozben T: Biomarkers associated with COVID-19 disease progression. Crit Rev Clin Lab Sci 57: 389-399, 2020.

18. Hu C, Liu Z, Jiang Y, Shi O, Zhang X, Xu K, Suo C, Wang Q, Song Y, Yu K, et al: Early prediction of mortality risk among patients with severe COVID-19, using machine learning. Int J Epidemiol 49: 1918-29, 2020.

19. Wynants L, Van Calster B, Collins GS, Riley RD, Heinze G, Schuit E, Bonten MMJ, Dahly DL, Damen JAA, Debray TPA, et al: Prediction models for diagnosis and prognosis of covid-19 infection: Systematic review and critical appraisal. BMJ 369: m1328, 2020.
20. Meng Z, Wang M, Zhao Z, Zhou Y, Wu Y, Guo S, Li M, Zhou Y, Yang S, Li W and Ying B: Development and validation of a predictive model for severe COVID-19: A Case-Control Study in China. Front Med (Lausanne) 8: 663145, 2021.

21. Álvarez-Mon M, Ortega MA, Gasulla Ó, Fortuny-Profitós J, Mazaira-Font FA, Saurina P, Monserrat J, Plana MN, Troncoso D, Moreno JS, et al: A predictive model and risk factors for case fatality of COVID-19. J Pers Med 11: 36, 2021.

22. Li Q, Zhang J, Ling Y, Li W, Zhang X, Lu H and Chen L: A simple algorithm helps early identification of SARS-CoV-2 infection patients with severe progression tendency. Infection 48: 577-584, 2020

23. Dong Y, Zhou H, Li M, Zhang Z, Guo W, Yu T, Gui Y, Wang Q, Zhao L, Luo S, et al: A novel simple scoring model for predicting severity of patients with SARS-CoV-2 infection. Transbound Emerg Dis 67: 2823-2829, 2020

24. Schwab P, DuMont Schütte A, Dietz B and Bauer S: Clinical predictive models for COVID-19: Systematic study. J Med Internet Res 22: e21439, 2020.

25. Ho JK, Jeevan-Raj B and Netter HJ: Hepatitis B Virus (HBV) subviral particles as protective vaccines and vaccine platforms. Viruses 12: 126, 2020.

26. D'Amelio E, Salemi S and D'Amelio R: Anti-Infectious human vaccination in historical perspective. Int Rev Immunol 35: 260-290, 2016.

27. Sanders B, Koldijk M and Schuitemaker H: Inactivated viral vaccines. In: Vaccine Analysis: Strategies, Principles, and Control. Nunnally BK, Turula VE and Sitrin RD (eds). Springer Berlin Heidelberg, Berlin, Heidelberg, pp45-80, 2015.

28. Donaldson B, Lateef Z, Walker GF, Young SL and Ward VK Virus-like particle vaccines: Immunology and formulation for clinical translation. Expert Rev Vaccines 17: 833-849, 2018.

29. World Health Organization (WHO): COVID-19 vaccine tracker and landscape. WHO, Geneva, 2021.https://www.who.int/publications/m/ item/draft-landscape-of-covid-19-candidate-vaccines. Accessed September 24, 2021

30. Lee WS, Wheatley AK, Kent SJ and DeKosky BJ: Antibody-dependent enhancement and SARS-CoV-2 vaccines and therapies. Nat Microbiol 5: 1185-1191, 2020.

31. Gao Q, Bao L, Mao H, Wang L, Xu K, Yang M, Li Y, Zhu L, Wang N, Lv Z, et al: Development of an inactivated vaccine candidate for SARS-CoV-2. Science 369: 77-81, 2020.

32. Zhang Y, Zeng G, Pan H, Li C, Hu Y, Chu K, Han W, Chen Z, Tang R, Yin W, et al: Safety, tolerability, and immunogenicity of an inactivated SARS-CoV-2 vaccine in healthy adults aged 18-59 years: A randomised, double-blind, placebo-controlled, phase 1/2 clinical trial. Lancet Infect Dis 21: 181-192, 2021.

33. Reuters: New Brazil Data Shows Disappointing 50.4\% Efficacy for China's CoronaVac Vaccine. Reuters, London, 2021. https://www.reuters.com/article/healthcoronavirus-brazil-coronavirus-idUSE5N2HA01G. Accessed February 3, 2021.

34. Tanriover MD, Doğanay HL, Akova M, Güner HR, Azap A, Akhan S, Köse Ş, Erdinç FŞ, Akalın EH, Tabak ÖF, et al: Efficacy and safety of an inactivated whole-virion SARS-CoV-2 vaccine (CoronaVac): Interim results of a double-blind, randomised, placebo-controlled, phase 3 trial in Turkey. Lancet 398: 213-222, 2021.

35. Soeriaatmadja W: ndonesia grants emergency use approval to Sinovac's vaccine, local trials show $65 \%$ efficacy. The StraitsTime, 2021. https://www.straitstimes.com/asia/se-asia/ indonesia-grants-emergency-use-approval-to-sinovac-vaccinelocal-trials-show-65. Updated January 12, 2021.

36. Wang H, Zhang Y, Huang B, Deng W, Quan Y, Wang W, Xu W, Zhao Y, Li N, Zhang J, et al: Development of an inactivated vaccine candidate, BBIBP-CorV, with potent protection against SARS-CoV-2. Cell 182: 713-721.e9, 2020.

37. Xia S, Zhang Y, Wang Y, Wang H, Yang Y, Gao GF, Tan W, $\mathrm{Wu}$ G, Xu M, Lou Z, et al: Safety and immunogenicity of an inactivated SARS-CoV-2 vaccine, BBIBP-CorV: A randomised, double-blind, placebo-controlled, phase 1/2 trial. Lancet Infect Dis 21: 39-51, 2021.

38. Ura T, Okuda K and Shimada M: Developments in viral Vector-Based vaccines. Vaccines (Basel) 2: 624-641, 2014.

39. Gsell PS, Camacho A, Kucharski AJ, Watson CH, Bagayoko A, Nadlaou SD, Dean NE, Diallo A, Diallo A, Honora DA, et al: Ring vaccination with rVSV-ZEBOV under expanded access in response to an outbreak of Ebola virus disease in Guinea, 2016: An operational and vaccine safety report. Lancet Infect Dis 17: 1276-1284, 2017 
40. Thomas SJ and Yoon IK: A review of Dengvaxia ${ }^{\circledR}$ : Development to deployment. Hum Vaccin Immunother 15: 2295-2314, 2019.

41. Pollard AJ, Launay O, Lelievre JD, Lacabaratz C, Grande S, Goldstein N, Robinson C, Gaddah A, Bockstal V, Wiedemann A, et al: Safety and immunogenicity of a two-dose heterologous Ad26.ZEBOV and MVA-BN-Filo Ebola vaccine regimen in adults in Europe (EBOVAC2): A randomised, observer-blind, participant-blind, placebo-controlled, phase 2 trial. Lancet Infect Dis 21: 493-506, 2021.

42. EU Clinical Trials Register: A phase I/II Study to Determine Efficacy Safety Immunogenicity of the Candidate Coronavirus Disease (COVID-19) Vaccine ChAdOx1 nCoV-19 in UK Healthy Adult Volunteers. European Medicines Agency, Amsterdam 2020. https://www.clinicaltrialsregister. eu/ctr-search/trial/2020-001072-15/GB. Accessed July 7, 2020

43. Logunov DY, Dolzhikova IV, Shcheblyakov DV, Tukhvatulin AI, Zubkova OV, Dzharullaeva AS, Kovyrshina AV, Lubenets NL, Grousova DM, Erokhova AS, et al: Safety and efficacy of an rAd26 and rAd5 vector-based heterologous prime-boost COVID-19 vaccine: An interim analysis of a randomised controlled phase 3 trial in Russia. Lancet 397: 671-681, 2021.

44. Mercado NB, Zahn R, Wegmann F, Loos C, Chandrashekar A, Yu J, Liu J, Peter L, McMahan K, Tostanoski LH, et al: Single-shot Ad26 vaccine protects against SARS-CoV-2 in rhesus macaques. Nature 586: 583-588, 2020

45. Zhu FC, Guan XH, Li YH, Huang JY, Jiang T, Hou LH, Li JX, Yang BF, Wang L, Wang WJ, et al: Immunogenicity and safety of a recombinant adenovirus type-5-vectored COVID-19 vaccine in healthy adults aged 18 years or older: A randomised, double-blind, placebo-controlled, phase 2 trial. Lancet 396: 479-488, 2020

46. Corbett KS, Edwards DK, Leist SR, Abiona OM, Boyoglu-Barnum S, Gillespie RA, Himansu S, Schäfer A, Ziwawo CT, DiPiazza AT, et al: SARS-CoV-2 mRNA vaccine design enabled by prototype pathogen preparedness. Nature 586 : 567-571, 2020

47. Walsh EE, Frenck RW Jr, Falsey AR, Kitchin N, Absalon J, Gurtman A, Lockhart S, Neuzil K, Mulligan MJ, Bailey R, et al: Safety and immunogenicity of two RNA-Based Covid-19 vaccine candidates N Engl J Med 383: 2439-2450, 2020

48. Mulligan MJ, Lyke KE, Kitchin N, Absalon J, Gurtman A, Lockhart S, Neuzil K, Raabe V, Bailey R, Swanson KA, et al: Phase I/II study of COVID-19 RNA vaccine BNT162b1 in adults. Nature 586: 589-593, 2020.

49. Motamedi H, Ari MM, Dashtbin S, Fathollahi M, Hossainpour H, Alvandi A, Moradi J and Abiri R: An update review of globally reported SARS-CoV-2 vaccines in preclinical and clinical stages. Int Immunopharmacol 96: 107763, 2021.

50. The Pirbright Institute: Studies at Pirbright Demonstrate Two Doses of Oxford University's COVID-19 Vaccine Boosts Immune Response In Pigs. The Pirbright Institute, Woking, 2020. https:// www.pirbright.ac.uk/press-releases/2020/06/studies-pirbrightdemonstrate-two-doses-oxford-university\%E2\%80\%99s-covid19-vaccine. Accessed July 10, 2020.

51. Folegatti PM, Ewer KJ, Aley PK, Angus B, Becker S, Belij-Rammerstorfer S, Bellamy D, Bibi S, Bittaye M, Clutterbuck EA, et al: Safety and immunogenicity of the ChAdOx1 nCoV-19 vaccine against SARS-CoV-2: A preliminary report of a phase $1 / 2$, single-blind, randomised controlled trial. Lancet 396: 467-478, 2020

52. South African Medical Research Council, South African Cochrane Centre: COVID-19 Vaccine (ChAdOx1 nCoV-19) trial in South African Adults with without HIV-Infection. South African Medical Research Council, South African Cochrane Centre, Tygerberg 2020. https://pactr.samrc.ac.za/TrialDisplay. aspx?TrialID=12166. Accessed July 7, 2020.

53. ISRCTN Registry: A Phase III Study to Investigate a Vaccine Against COVID-19. ISRCTN Registry, London, 2020 http://www.isrctn.com/ISRCTN89951424. Accessed August 20, 2020.

54. US National Library of Medicine (NIH): Phase III Doubleblind, Placebo-controlled Study of AZD1222 for the Prevention of COVID-19 in Adults. ClinicalTrials.gov Identifier: NCT04516746. NIH, Bethesda, MD, 2020. https://clinicaltrials. gov/ct2/show/NCT04516746. Accessed August 20, 2020.

55. Voysey M, Clemens SAC, Madhi SA, Weckx LY, Folegatti PM Aley PK, Angus B, Baillie VL, Barnabas SL, Bhorat QE, et al: Safety and efficacy of the ChAdOx1 nCoV-19 vaccine (AZD1222) against SARS-CoV-2: An interim analysis of four randomised controlled trials in Brazil, South Africa, and the UK. Lancet 397: 99-111, 2021
56. Wang P, Nair MS, Liu L, Iketani S, Luo Y, Guo Y, Wang M, Yu J, Zhang B, Kwong PD, et al: Antibody resistance of SARS-CoV-2 variants B.1.351 and B.1.1.7. Nature 593: $130-135,2021$

57. Madhi SA, Baillie V, Cutland CL, Voysey M, Koen AL, Fairlie L, Padayachee SD, Dheda K, Barnabas SL, Bhorat QE, et al: Efficacy of the ChAdOx1 nCoV-19 Covid-19 vaccine against the B.1.351 variant. N Engl J Med 384: 1885-1898, 2021.

58. Dejnirattisai W, Zhou D, Supasa P, Liu C, Mentzer AJ, Ginn HM, Zhao Y, Duyvesteyn HME, Tuekprakhon A, Nutalai R, et al: Antibody evasion by the P.1 strain of SARS-CoV-2. Cell 184: 2939-2954.e9, 2021.

59. Public Health England: Public Health England vaccine effectiveness report March 2021. Public Health England, London, 2021. https://assets.publishing.service.gov.uk/government/uploads/ system/uploads/attachment_data/file/989360/PHE_COVID-19_ vaccine_effectiveness_report_March_2021_v2.pdf.

60. Shah ASV, Gribben C, Bishop J, Hanl n P, Caldwell D, Wood R, Reid M, McMenamin J, Goldberg D, Stockton D, et al: Effect of vaccination on transmission of COVID-19: an observational study in healthcare workers and their households. medRxiv: doi: https://doi.org/10.1101/2021.03.11.21253275.

61. COVID-19 vaccine AstraZeneca analysis print. Report Run Date: 22-Mar-2021 Data Lock Date: 14-Mar-2021 19:00:03 Al UK spontaneous reports received between 4/01/21 and 14/03/21 for COVID-19 vaccine Oxford University/AstraZeneca. https:// it.scribd.com/document/503301908/COVID-19-AstraZenecaVaccine-Analysis-Print. Accessed March 22, 2021.

62. Greinacher A, Thiele T, Warkentin TE, Weisser K, Kyrle PA and Eichinger S: Thrombotic thrombocytopenia after ChAdOx1 nCov-19 vaccination. N Engl J Med 384: 2092-2101, 2021.

63. Schultz NH, Sørvoll IH, Michelsen AE, Munthe LA, Lund-Johansen F, Ahlen MT, Wiedmann M, Aamodt AH, Skattør TH, Tjønnfjord GE and Holme PA: Thrombosis and thrombocytopenia after $\mathrm{ChAdOx} 1 \mathrm{nCoV}-19$ vaccination. $\mathrm{N}$ Engl J Med 384: 2124-2130, 2021.

64. Scully M, Singh D, Lown R, Poles A, Solomon T, Levi M, Goldblatt D, Kotoucek P, Thomas W and Lester W: Pathologic antibodies to platelet factor 4 after ChAdOx1 nCoV-19 vaccination. N Engl J Med 384: 2202-2211, 2021.

65. Bayas A, Menacher M, Christ M, Behrens L, Rank A and Naumann M: Bilateral superior ophthalmic vein thrombosis, ischaemic stroke, and immune thrombocytopenia after ChAdOx1 nCoV-19 vaccination. Lancet 397: e11, 2021.

66. Wolf ME, Luz B, Niehaus L, Bhogal P, Bäzner H and Henkes H: Thrombocytopenia and intracranial Venous Sinus thrombosis after 'COVID-19 vaccine AstraZeneca' exposure. J Clin Med 10: 1599, 2021.

67. Bjørnstad-Tuveng TH, Rudjord A and Anker P: Fatal cerebral haemorrhage after COVID-19 vaccine. Tidsskr Nor Laegeforen 141, 2021 (In English, Norwegian).

68. Pottegård A, Lund LC, Karlstad Ø, Dahl J, Andersen M, Hallas J, Lidegaard Ø, Tapia G, Gulseth HL, Ruiz PL, et al: Arterial events, venous thromboembolism, thrombocytopenia, and bleeding after vaccination with Oxford-AstraZeneca ChAdOx1-S in Denmark and Norway: Population based cohort study. BMJ 373: n1114, 2021.

69. European Medicined Agency (EMA): AstraZeneca's COVID-19 vaccine: EMA finds possible link to very rare cases of unusual blood clots with low blood platelets. EMA, Amsterdam, 2021. https://www.ema.europa.eu/en/news/astrazenecas-covid-19-vaccine-ema-finds-possible-link-very-rare-cases-unusual-blood-clot s-low-blood. Accessed April 7, 2021

70. Sadoff J, Le Gars M, Shukarev G, Heerwegh D, Truyers C, de Groot AM, Stoop J, Tete S, Van Damme W, Leroux-Roels I, et al: Interim Results of a Phase 1-2a Trial of Ad26.COV2.S Covid-19 vaccine. N Engl J Med 384: 1824-1835, 2021.

71. Sadoff J, Gray G, Vandebosch A, Cárdenas V, Shukarev G, Grinsztejn B, Goepfert PA, Truyers C, Fennema H, Spiessens B, et al: Safety and efficacy of single-dose Ad26.COV2.S vaccine against Covid-19. N Engl J Med 384: 2187-2201, 2021.

72. Jongeneelen M, Kaszas K, Veldman D, Huizingh J, van der Vlugt $R$, Schouten T, Zuijdgeest D, Uil T, van Roey G, Guimera N, et al: Ad26.COV2.S elicited neutralizing activity against Delta and other SARS-CoV-2 variants of concern. bioRxiv: doi: https://doi.org/10.1101/2021.07.01.450707.

73. JanssenMD ${ }^{\circledR}$ : Janssen COVID-19 Vaccine - Adverse Event - Hypersensitivity and Anaphylaxis Reactions. https://www. janssenmd.com/janssen-covid19-vaccine/safety/hypersensitivityreactions/janssen-covid19-vaccine-adverse-event-hypersensitivityand-anaphylaxis-reactions. Last Updated July 15, 2021. 
74. HCP Live: Janssen's COVID-19 Vaccine Shows Efficacy in Phase 3 Data. https://www.hcplive.com/view/janssen-covid-19vaccine-efficacy-phase-3-data. Accessed February 24, 2021.

75. See I, Su JR, Lale A, Woo EJ, Guh AY, Shimabukuro TT, Streiff MB, Rao AK, Wheeler AP, Beavers SF, et al: US case reports of Cerebral Venous Sinus thrombosis with thrombocytopenia after Ad26.COV2.S vaccination, March 2 to April 21 2021. JAMA 325: 2448-2456, 2021.

76. Ophinni Y, Hasibuan AS, Widhani A, Maria S, Koesnoe S, Yunihastuti E, Karjadi TH, Rengganis I and Djauzi S: COVID-19 vaccines: Current status and implication for use in Indonesia. Acta Med Indones 52: 388-412, 2020.

77. Jackson LA, Anderson EJ, Rouphael NG, Roberts PC, Makhene M, Coler RN, McCullough MP, Chappell JD, Denison MR, StevensLJ,etal: AnmRNA vaccine againstSARS-CoV-2-Preliminary Report. N Engl J Med 383: 1920-1931, 2020.

78. MishraS: An Infectious Disease ExpertExplains The Results from Moderna's Latest Vaccine Trials. The Conversation Trust (UK), London, 2020. https://theconversation.com/video-an-infectiousdisease-expert-explains-the-results-from-modernas-latest-vacci ne-trials-142888. Accessed July 18, 2020.

79. US National Library of Medicine (NIH): Dose-Confirmation Study to Evaluate the Safety Reactogenicity and Immunogenicity of mRNA-1273 COVID-19 Vaccine in Adults Aged 18 Years and Older. ClinicalTrials.gov Identifier: NCT04405076. NIH, Bethesda, MD, 2020. https://clinicaltrials.gov/ct2/show/NCT04405076?term $=$ moderna\&cond=covid-19\&draw $=2$. Accessed July 6, 2020 .

80. Baden LR, El Sahly HM, Essink B, Kotloff K, Frey S, Novak R, Diemert D, Spector SA, Rouphael N, Creech CB, et al: Efficacy and safety of the mRNA-1273 SARS-CoV-2 vaccine. N Engl J Med 384: 403-416, 2021.

81. US NationalLibrary of Medicine(NIH): A Study toEvaluate Safetyand Effectiveness of mRNA-1273 Vaccine in Healthy Children Between 6 Months of Age and Less Than 12 Years of Age. NIH, Bethesda, MD, 2021. https://clinicaltrials.gov/ct2/history/NCT04796896?V_1=View. Accessed March 11, 2021.

82. Wu K, Werner AP, Koch M, Choi A, Narayanan E, Stewart-Jones GBE, Colpitts T, Bennett H, Boyoglu-Barnum S, Shi W, et al: Serum neutralizing activity elicited by mRNA-1273 vaccine. N Engl J Med 383: 2427-2438, 2021

83. Planas D, Bruel T, Grzelak L, Guivel-Benhassine F, Staropoli I, Porrot F, Planchais C, Buchrieser J, Rajah MM, Bishop E, et al: Sensitivity of infectious SARS-CoV-2 B.1.1.7 and B.1.351 variants to neutralizing antibodies. Nat Med 27: 917-924, 2021.

84. Wu K, Werner AP, Moliva JI, Koch M, Choi A, Stewart-Jones GBE, Bennett H, Boyoglu-Barnum S, Shi W, Graham BS, et al: mRNA-1273 vaccine induces neutralizing antibodies against spike mutants from global SARS-CoV-2 variants. bioRxiv: doi: https://doi. org/10.1101/2021.01.25.427948.

85. GOV.UK: Decision. Summary of Product Characteristics for Spikevax. https://www.gov.uk/government/ publications/regulatory-approval-of-covid-19-vaccine-moderna/ information-for-healthcare-professionals-on-covid-19-vaccinemoderna. Updated August 20, 2021

86. Vaccines and Related Biological Products Advisory Committee Meeting Date: 17 December 2020. https://www. fda.gov/advisory-committees/advisory-committee-calendar/ vaccines-and-related-biological-products-advisory-committeedecember-17-2020-meeting-announcement. Accessed December 17, 2020.

87. Walsh EE, Frenck RW Jr, Falsey AR, Kitchin N, Absalon J, Gurtman A, Lockhart S, Neuzil K, Mulligan MJ, Bailey R, et al: Safety and immunogenicity of two RNA-based Covid-19 vaccine candidates. N Engl J Med 383: 2439-2450, 2020

88. Polack FP, Thomas SJ, Kitchin N, Absalon J, Gurtman A, Lockhart S, Perez JL, Pérez Marc G, Moreira ED, Zerbini C, et al: Safety and efficacy of the BNT162b2 mRNA Covid-19 vaccine. N Engl J Med 383: 2603-2615, 2020.

89. Lopez Bernal J, Andrews N, Gower C, Robertson C Stowe J, Tessier E, Simmons R, Cottrell S, Roberts R, O'Doherty M, et al: Effectiveness of the Pfizer-BioNTech and Oxford-AstraZeneca vaccines on covid-19 related symptoms, hospital admissions, and mortality in older adults in England: test negative case-control study. BMJ 373: n1088, 2021.

90. Pritchard E, Matthews PC, Stoesser N, Eyre DW, Gethings O, Vihta KD, Jones J, House T, VanSteenHouse H, Bell I, et al: Impact of vaccination on new SARS-CoV-2 infections in the United Kingdom. Nat Med 27: 1370-1378, 2021.
91. Hall VJ, Foulkes S, Saei A, Andrews N, Oguti B, Charlett A Wellington E, Stowe J, Gillson N, Atti A, et al: COVID-19 vaccine coverage in health-care workers in England and effectiveness of BNT162b2 mRNA vaccine against infection (SIREN): A prospective, multicentre, cohort study. Lancet 397: $1725-1735,2021$

92. Pfizer: Pfizer and BioNTech Confirm High Efficacy and No Serious Safety Concerns Through Up to Six Months Following Second Dose in Updated Topline Analysis of Landmark COVID-19 Vaccine Study. Pfizer, New York, NY, 2021. https://www.pfizer. $\mathrm{com} /$ news/press-release/press-release-detail/pfizer-and-biontechconfirm-high-efficacy-and-no-serious. Accessed April 1, 2021

93. Dejnirattisai W, Zhou D, Supasa P, Liu C, Mentzer AJ, Ginn HM, Zhao Y, Duyvesteyn HME, Tuekprakhon A, Nutalai $\mathrm{R}$, et al: Antibody evasion by the P.1 strain of SARS-CoV-2 Cell 184: 2939-2954, 2021.

94. Parry H, Bruton R, Tut G, Ali M, Stephens C, Greenwood D, Faustini S, Hughes S, Huissoon A, Meade R, et al: Immunogenicity of single vaccination with BNT162b2 or ChAdOx1 nCoV-19 at 5-6 weeks post vaccine in participants aged 80 years or older: An exploratory analysis. Lancet Healthy Longev 2: e554-e560, 2021.

95.Lustig Y, Zuckerman N, Nemet I, Atari N, Kliker L, Regev-Yochay G, Sapir E, Mor O, Alroy-Preis S, Mendelson E and Mandelboim M: Neutralising capacity against Delta (B.1.617.2) and other variants of concern following Comirnaty (BNT162b2, BioNTech/Pfizer) vaccination in health care workers Israel. Euro Surveill 26: 2100557, 2021.

96. Hacisuleyman E, Hale C, Saito Y, Blachere NE, Bergh M, Conlon EG, Schaefer-Babajew DJ, DaSilva J, Muecksch F, Gaebler C, et al: Vaccine breakthrough infections with SARS-CoV-2 Variants. N Engl J Med 384: 2212-2218, 2021.

97. Geers D, Shamier MC, Bogers S, den Hartog G, Gommers L, Nieuwkoop NN, Schmitz KS, Rijsbergen LC, van Osch JAT, Dijkhuizen E, et al: SARS-CoV-2 variants of concern partially escape humoral but not $\mathrm{T}$-cell responses in COVID-19 convalescent donors and vaccinees. Sci Immunol 6: eabj1750, 2021

98. Public Health England: Public Health England vaccine effectiveness report March 2021. https://www.gov.uk/government/ publications/phe-monitoring-of-the-effectiveness-of-covid19-vaccination. Accessed March 17, 2021.

99. Levine-Tiefenbrun M, Yelin I, Katz R, Herzel E, Golan Z, Schreiber L, Wolf T, Nadler V, Ben-Tov A, Kuint J, et al: Initial report of decreased SARS-CoV-2 viral load after inoculation with the BNT162b2 vaccine. Nat Med 27: 790-792, 2021

100. Angel Y, Spitzer A, Henig O, Saiag E, Sprecher E, Padova H and Ben-Ami R: Association between vaccination with BNT162b2 and incidence of symptomatic and asymptomatic SARS-CoV-2 infections among health care workers. JAMA 325: 2457-2465, 2021.

101. Haas EJ, Angulo FJ, McLaughlin JM, Anis E, Singer SR, Khan F, Brooks N, Smaja M, Mircus G, Pan K, et al: Impact and effectiveness of mRNA BNT162b2 vaccine against SARS-CoV-2 infections and COVID-19 cases, hospitalisations, and deaths following a nationwide vaccination campaign in Israel: An observational study using national surveillance data. Lancet 397: 1819-1829, 2021.

102. Jones NK, Rivett L, Seaman S, Samworth RJ, Warne B, Workman C, Ferris M, Wright J, Quinnell N, Shaw A, et al: Single-dose BNT162b2 vaccine protects against asymptomatic SARS-CoV-2 infection. Elife 10: e68808, 2021.

103.GOV.UK: COVID-19 mRNA Pfizer-BioNTech vaccine analysis print. https://assets.publishing.service.gov.uk/government/uploads/system/uploads/attachment_data/file/1020030/ COVID-19_mRNA_Pfizer-_BioNTech_vaccine_analysis_ print.pdf. Accessed September 17, 2021.

104. Chapin-Bardales J, Gee J and Myers T: Reactogenicity following receipt of mRNA-Based COVID-19 vaccines. JAMA 325: 2201-2202, 2021

105. Meo SA, Bukhari IA, Akram J, Meo AS and Klonoff DC: COVID-19 vaccines: Comparison of biological, pharmacological characteristics and adverse effects of Pfizer/BioNTech and Moderna vaccines. Eur Rev Med Pharmacol Sci 25: 1663-1669, 2021

106. Bhattacharjee S and Banerjee M: Immune Thrombocytopenia Secondary to COVID-19: A systematic review. SN Compr Clin Med: Sep 19, 2020 (Epub ahead of print).

107. Weyrich AS, Schwertz H, Kraiss LW and Zimmerman GA Protein synthesis by platelets: Historical and new perspectives. J Thromb Haemost 7: 241-246, 2009. 
108. Raadsen M, Du Toit J, Langerak T, van Bussel B, van Gorp E and Goeijenbier M: Thrombocytopenia in virus Infections. J Clin Med 10: 877, 2021.

109. Welsh KJ, Baumblatt J, Chege W, Goud R and Nair N: Thrombocytopenia including immune thrombocytopenia after receipt of mRNA COVID-19 vaccines reported to the Vaccine Adverse Event Reporting System (VAERS). Vaccine 39: 3329-3332, 2021.

110. Guimarães LE, Baker B, Perricone C and Shoenfeld Y: Vaccines, adjuvants and autoimmunity. Pharmacol Res 100 190-209, 2015.

111. European Medicined Agency (EMA): COVID-19 Vaccine AstraZeneca: PRAC investigating cases of thromboembolic events - vaccine's benefits currently still outweigh risks - Update. EMA, Amsterdam, 2021. https://www.ema.europa.eu/en/news/ covid-19-vaccine-astrazeneca-prac-investigating-cases-thromboembolic-events-vaccines-benefits. Accessed March 11, 2021.

112. Shimabukuro TT, Kim SY, Myers TR, Moro PL, Oduyebo T, Panagiotakopoulos L, Marquez PL, Olson CK, Liu R, Chang KT, et al: Preliminary findings of mRNA COVID-19 vaccine safety in pregnant persons. N Engl J Med 384: 2273-2282, 2021.

113. García-Montero C, Fraile-Martínez O, Bravo C Torres-Carranza D, Sanchez-Trujillo L, Gómez-Lahoz AM Guijarro LG, García-Honduvilla N, Asúnsolo A, Bujan J, et al: An updated review of SARS-CoV-2 vaccines and the importance of effective vaccination programs in pandemic times. Vaccines (Basel) 9: 433, 2021.

114. GOV.UK: Vaccinations in United Kingdom. https://coronavirus. data.gov.uk/details/vaccinations. Last Updated September 26, 2021

115. Office of National Statistics (ONS): Coronavirus (COVID-19) latest insights. ONS, London, 2021. https://www.ons.gov.uk/peoplepopulationandcommunity/healthandsocialcare/conditionsanddiseases/ articles/coronaviruscovid19/latestinsights.

116. Wei J, Stoesser N, Matthews PC, Ayoubkhani D, Studley R, Bell I, Bell JI, Newton JN, Farrar J, Diamond I, et al: Antibody responses to SARS-CoV-2 vaccines in 45,965 adults from the general population of the United Kingdom. Nat Microbiol 6 : $1140-1149,2021$

117. Dagan N, Barda N, Kepten E, Miron O, Perchik S, Katz MA Hernán MA, Lipsitch M, Reis B and Balicer RD: BNT162b2 mRNA Covid-19 vaccine in a Nationwide mass vaccination setting. N Engl J Med 384: 1412-1423, 2021.

118. Shrotri M, Navaratnam AMD, Nguyen V, Byrne T, Geismar C, Fragaszy E, Beale S, Fong WLE, Patel P, Kovar J, et al: Spike-antibody waning after second dose of BNT162b2 or ChAdOx1. Lancet 398: 385-387, 2021.

119. Rossman H, Shilo S, Meir T, Gorfine M, Shalit U and Segal E: COVID-19 dynamics after a national immunization program in Israel. Nat Med 27: 1055-1061, 2021.

120.European Centre for Disease Prevention and Control (ECDC): Rapid risk assessment: Assessing SARS-CoV-2 circulation, variants of concern, non-pharmaceutical interventions and vaccine rollout the EU/EEA 15th update ECDC, Stockholm, 2021. https://www.ecdc.europa. eu/en/publications-data/rapid-risk-assessment-sars-cov-2-circulation-variants-concern. Accessed June 10, 2021.

121. McNamara D: Delta Variant Key to Breakthrough Infections in Vaccinated Israelis. Medscape, 2021. https://www.medscape. com/viewarticle/954357. Accessed July 7, 2021

122.GOV.UK: Investigation of SARS-CoV-2 variants of concern: technical briefings. https://www.gov.uk/government/publications/investigation-of-novel-sars-cov-2-variant-variant-of-con cern-20201201. Accessed December 21, 2020.

123. Lopez Bernal J, Andrews N, Gower C, Gallagher E, Simmons R, Thelwall S, Stowe J, Tessier E, Groves N, Dabrera G, et al: Effectiveness of Covid-19 vaccines against the B.1.617.2 (Delta) Variant. N Engl J Med 385: 585-594, 2021.

124. Barouch DH, Stephenson KE, Sadoff J, Yu J, Chang A, Gebre M McMahan K, Liu J, Chandrashekar A, Patel S, et al: Durable humoral and cellular immune responses 8 months after Ad26. COV2.S vaccination. N Engl J Med 385: 951-953, 2021.

125. Sheikh A, McMenamin J, Taylor B and Robertson C; Public Health Scotland and the EAVE II Collaborators: SARS-CoV-2 Delta VOC in Scotland: Demographics, risk of hospital admission, and vaccine effectiveness. Lancet 397: 2461-2462, 2021

126. Choi A, Koch M, Wu K, Dixon G, Oestreicher J, Legault H, Stewart-Jones GBE, Colpitts T, Pajón R, Bennett H, et al: Serum neutralizing activity of mRNA-1273 against SARS-CoV-2 Variants. J Virol JVI0131321, 2021 (Epub ahead of print).
127. Nasreen S, Chung H, K. He S, Brown A, Gubbay JB, Buchan SA, Fell DB, Austin PC, Schwartz KL, M. Sndaram ME, et al: Effectiveness of COVID-19 vaccines against variants of concern, Canada. medRxiv: doi: https://doi.org/10.1101/2021.06.28.21259420.

128. Tada T, Zhou H, Samanovic MI, Dcosta BM, Cornelius A, Mulligan MJ and Landau NR: Comparison of neutralizing antibody Titers Elicited by mRNA and Adenoviral vector vaccine against SARS-CoV-2 Variants. bioRxiv: doi: 10.1101/2021.07.19.452771.

129. Nanduri S, Pilishvili T, Derado G, Soe MM, Dollard P, Wu H, Li Q, Bagchi S, Dubendris H, Link-Gelles R, et al: Effectiveness of Pfizer-BioNTech and Moderna vaccines in preventing SARS-CoV-2 infection among nursing home residents before and during widespread circulation of the SARS-CoV-2 B.1.617.2 (Delta) Variant-National Healthcare Safety Network, March 1-August 1, 2021. MMWR Morb Mortal Wkly Rep 70: 1163-1166, 2021

130. Centers for Disease Control and Prevention (CDC): Interim Clinical Considerations for Use of COVID-19 Vaccines Currently Approved or Authorized in the United States. CDC, Atlanta, GA, 2021. https://www.cdc.gov/vaccines/covid-19/clinical-considerations/covid-19-vaccines-us.html. Last Updated September 15, 2021

131. Centers for Disease Control and Prevention (CDC): Understanding mRNA COVID-19 Vaccines. CDC, Atlanta, GA, 2021. https://www.cdc.gov/coronavirus/2019-ncov/vaccines/differentvaccines/mrna.html. Accessed March 4, 2021.

132. Zhang C, Maruggi G, Shan $\mathrm{H}$ and Li J: Advances in mRNA vaccines for infectious diseases. Front Immunol 10: 594, 2019.

133. Jackson NAC, Kester KE, Casimiro D, Gurunathan S and DeRosa F: The promise of mRNA vaccines: A biotech and industrial perspective. NPJ Vaccines 5: 11, 2020.

134. Zhang NN, Li XF, Deng YQ, Zhao H, Huang YJ, Yang G, Huang WJ, Gao P, Zhou C, Zhang RR, et al: A Thermostable mRNA vaccine against COVID-19. Cell 182: 1271-1283.e16, 2020.

135. Gray R: Q\&A: How Covid-19 hijacks human cells. European Commission, Luxembourg, 2020. https://ec.europa. eu/research-and-innovation/en/horizon-magazine/qa-how-covid -19-hijacks-human-cells. Accessed December 15, 2020

136. Lindsay KE, Bhosle SM, Zurla C, Beyersdorf J, Rogers KA, Vanover D, Xiao P, Araínga M, Shirreff LM, Pitard B, et al: Visualization of early events in mRNA vaccine delivery in non-human primates via PET-CT and near-infrared imaging. Nat Biomed Eng 3: 371-380, 2019.

137. Desigaux L,Sainlos M,Lambert O,Chevre R,Letrou-BonnevalE, Vigneron JP, Lehn P, Lehn JM and Pitard B: Self-assembled lamellar complexes of siRNA with lipidic aminoglycoside derivatives promote efficient siRNA delivery and interference. Proc Natl Acad Sci USA 104: 16534-16539, 2007.

138. Frey SE, Wald A, Edupuganti S, Jackson LA, Stapleton JT, El Sahly H, El-Kamary SS, Edwards K, Keyserling H, Winokur $\mathrm{P}$, et al: Comparison of lyophilized versus liquid modified vaccinia Ankara (MVA) formulations and subcutaneous versus intradermal routes of administration in healthy vaccinia-naïve subjects. Vaccine 33: 5225-5234, 2015

139. Habrant D, Peuziat P, Colombani T, Dallet L, Gehin J, Goudeau E, Evrard B, Lambert O, Haudebourg T and Pitard B: Design of ionizable lipids to overcome the limiting step of endosomal escape: Application in the intracellular delivery of mRNA, DNA, and siRNA. J Med Chem 59: 3046-3062, 2016.

140. Caballero ML, Krantz MS, Quirce S, Phillips EJ and Stone CA Jr: Hidden dangers: Recognizing excipients as potential causes of drug and vaccine hypersensitivity reactions. J Allergy Clin Immunol Pract 9: 2968-2982, 2021.

141. Banerji A, Wickner PG, Saff R, Stone CA Jr, Robinson LB, Long AA, Wolfson AR, Williams P, Khan DA, Phillips E and Blumenthal KG: mRNA vaccines to prevent COVID-19 disease and reported allergic reactions: Current evidence and suggested approach. J Allergy Clin Immunol Pract 9: 1423-1437, 2021

142. Cabanillas B, Akdis C and Novak N: Allergic reactions to the first COVID-19 vaccine: A potential role of Polyethylene glycol? Allergy 76: 1617-1618, 2021.

143. Garvey LH and Nasser S: Anaphylaxis to the first COVID-19 vaccine: Is polyethylene glycol (PEG) the culprit? $\mathrm{Br}$ J Anaesth 126: e106-e108, 2021.

144. Yu RJ, Krantz MS, Phillips EJ and Stone CA Jr: Emerging causes of drug-induced anaphylaxis: A review of anaphylaxis-associated reports in the FDA Adverse Event Reporting System (FAERS). J Allergy Clin Immunol Pract 9: 819-829.e2, 2021. 
145. Chung CH, Mirakhur B, Chan E, Le QT, Berlin J, Morse M, Murphy BA, Satinover SM, Hosen J, Mauro D, et al: Cetuximab-induced anaphylaxis and $\operatorname{IgE}$ specific for galactose-alpha-1,3-galactose. N Engl J Med 358: 1109-1117, 2008.

146. Wenande E and Garvey LH: Immediate-type hypersensitivity to polyethylene glycols: A review. Clin Exp Allergy 46: 907-922, 2016.

147. Centers for Disease Control and Prevention (CDC): When You've Been Fully Vaccinated. How to Protect Yourself and Others. CDC, Atlanta, GA, 2021. https://www.cdc. gov/coronavirus/2019-ncov/vaccines/fully-vaccinated.html. Updated September 16, 2021.

148. Mazagatos C, Monge S, Olmedo C, Vega L, Gallego P, Martín-Merino E, Sierra MJ, Limia A and Larrauri A; Working Group for the surveillance and control of COVID-19 in Spain Working group for the surveillance and control of COVID-19 in Spain: Effectiveness of mRNA COVID-19 vaccines in preventing SARS-CoV-2 infections and COVID-19 hospitalisations and deaths in elderly long-term care facility residents, Spain, weeks 532020 to 13 2021. Euro Surveill 26: 2100452, 2021.

149. Centers for Disease Control and Prevention (CDC): Coronavirus Disease 2019 (COVID-19), People who are at higher risk for severe illness. CDC, Atlanta, GA, 2021. https://www.cdc.gov/coronavirus/2019-ncov/need-extra-precautions/groups-at-higher-risk.html. Updated August 20, 2021].

150. Dan JM, Mateus J, Kato Y, Hastie KM, Yu ED, Faliti CE, Grifoni A, Ramirez SI, Haupt S, Frazier A, et al: Immunological memory to SARS-CoV-2 assessed for up to 8 months after infection. Science 371: eabf4063, 2021.

151. Centers for Disease Control and Prevention (CDC): When You've Been Fully Vaccinated. How to Protect Yourself and Others. CDC, Atlanta, GA, 2021. https://www.cdc.gov/coronavirus/2019$\mathrm{ncov} /$ vaccines/fully-vaccinated-guidance.html. Updated September 16, 2021.
152. Foy BH, Wahl B, Mehta K, Shet A, Menon GI and Britto C: Comparing COVID-19 vaccine allocation strategies in India: A mathematical modelling study. Int J Infect Dis 103: 431-438, 2021.

153. Gokbulut N, Kuymakamzade B, Sanlidag T and Hincal E: Mathematical modelling of Covid-19 with the effect of vaccine. AIP Conference Proceedings 2325: 020065, 2021.

154. Jentsch PC, Anand M and Bauch CT: Prioritising COVID-19 vaccination in changing social and epidemiological landscapes: A mathematical modelling study. Lancet Infect Dis 21: 1097-1106, 2021.

155. Martinez-Rodriguez D, Gonzalez-Parra G and Villanueva RJ: Analysis of key factors of a SARS-CoV-2 vaccination program: A mathematical modeling approach. Epidemiologia 2: 140-161, 2021

156. Webb G: A COVID-19 epidemic model predicting the effectiveness of vaccination in the US. Infect Dis Rep 13: 654-667, 2021.

157. Chaturvedi D and Chakravarty U: Predictive analysis of COVID-19 eradication with vaccination in India, Brazil, and USA. Infect Genet Evol 92: 104834, 2021.

158. McDonnell A, Van Exan R, Lloyd S, Subramanian L, Chalkidou K, La Porta A, Li J, Maiza E, Reader D, Rosenberg J, et al: COVID-19 Vaccine predictions: Using mathematical modelling and expert opinions to estimate timelines and probabilities of success of COVID-19 vaccines. Center for Global Development, Washington, DC, 2020. https://www. cgdev.org/publication/covid-19-vaccine-predictions. Accessed October 1, 2020.

cc) (i) $\odot$ This work is licensed under a Creative Commons Attribution-NonCommercial-NoDerivatives 4.0 International (CC BY-NC-ND 4.0) License. 